NBER WORKING PAPER SERIES

\title{
DISCOUNT RATE RISK IN PRIVATE EQUITY: EVIDENCE FROM SECONDARY MARKET TRANSACTIONS
}

\author{
Brian Boyer \\ Taylor D. Nadauld \\ Keith P. Vorkink \\ Michael S. Weisbach \\ Working Paper 28691 \\ http://www.nber.org/papers/w28691
NATIONAL BUREAU OF ECONOMIC RESEARCH
1050 Massachusetts Avenue
Cambridge, MA 02138
April 2021

We are grateful to the partners at an anonymous intermediary for providing us with data. We thank Ulf Axelson, Carter Davis, Pierre Collin-Dufresne, Brigham Frandsen, Jason Gull, Niklas Hüther, Jonathan Jensen, Steve Kaplan, Arthur Korteweg, Josh Lerner, Stefan Nagel, Ludovic Phalippou, Joseph Romano, Amit Seru, Tyler Shumway, Per Strömberg, Ayako Yasuda, Jeffrey Wooldridge, two anonymous referees, and seminar and conference participants at Brigham Young University, the University of Chicago Housing and Corporate Lending Conference, Ensign Peak Advisors, the Finance Research Association, Lausanne, London Business School, Miami, the NBER Corporate Finance Meetings, Ohio State, Singapore Management University, Texas Tech, and the Wasatch Finance Conference, for useful comments and suggestions. We also thank Greg Adams and Hyeik Kim for excellent research assistance. The views expressed herein are those of the authors and do not necessarily reflect the views of the National Bureau of Economic Research.

NBER working papers are circulated for discussion and comment purposes. They have not been peer-reviewed or been subject to the review by the NBER Board of Directors that accompanies official NBER publications.

(C) 2021 by Brian Boyer, Taylor D. Nadauld, Keith P. Vorkink, and Michael S. Weisbach. All rights reserved. Short sections of text, not to exceed two paragraphs, may be quoted without explicit permission provided that full credit, including $\odot$ notice, is given to the source. 
Discount Rate Risk in Private Equity: Evidence from Secondary Market Transactions

Brian Boyer, Taylor D. Nadauld, Keith P. Vorkink, and Michael S. Weisbach

NBER Working Paper No. 28691

April 2021

JEL No. G11,G23,G24

\section{ABSTRACT}

Standard measures of private equity performance based on cash flows overlook discount rate risk. An index constructed from prices paid in secondary market transactions indicates that private equity discount rates vary considerably. While the standard alpha for our index is zero, measures of performance based on cash flow data for funds in our index are large and positive. To illustrate that results are not driven by idiosyncrasies of private equity secondary markets, we obtain similar results using cash flows and returns of synthetic funds that invest in small cap stocks. Ignoring variation in PE discount rates can lead to a misallocation of capital.

Brian Boyer

Marriott School of Management

Brigham Young University

Provo, UT 84602

bhb@byu.edu

Taylor D. Nadauld

Department of Finance

Brigham Young University

Provo, Utah 84602

taylor.nadauld@byu.edu
Keith P. Vorkink

Finance Department

Marriott School

Brigham Young University

Office 634 TNRB

Provo, UT 84602-3113

keith_vorkink@byu.edu

Michael S. Weisbach

Department of Finance

Fisher College of Business

Ohio State University

2100 Neil Ave.

Columbus, $\mathrm{OH} 43210$

and NBER

weisbach.2@osu.edu 


\section{Introduction}

In recent decades, private equity $(\mathrm{PE})$ has become an important asset class for investors. A recent survey of institutional investors finds that $88 \%$ are invested in private equity, with nearly a third having an allocation greater than 10\% (Whyte (2017)). In the early 2000s, a secondary market developed in which limited partners (LPs) can transact their stakes in private equity funds. ${ }^{1}$ Since data on secondary market prices are not publicly-available, investors and academics have been limited to using data on cash-flows to evaluate the risk and return of private equity. As much as half of the variation for public equity returns, however, is driven by news about discount rates (Campbell (1991). Further, all variation in dividend price ratios for public equity corresponds to variation in discount rates, not variation in expected cash flows (Campbell and Shiller (1989), Campbell (2011)).

These findings naturally lead to four important questions to consider. First, under what conditions might performance measures based on cash flows overlook risk that arises from variation in discount rates? After all, asset prices are not arbitrary and should ultimately be determined by the properties of the underlying cash flows. Second, to what extent do discount rates for private equity vary? The marginal PE investor may very well differ from the marginal investor in other asset classes in terms of preferences, sophistication, sentiment, and risk aversion that are all important determinants for discount rates. Moreover, the organizational structure of private equity may generate unique risk dynamics. Third, how does variation in PE discount rates impact standard performance measures such as CAPM alpha and beta, relative to other measures of performance based on cash flows? And fourth, what kind of investor cares about variation in PE discount rates?

To answer the first question, we explore the relationship between the GPME of Korteweg and Nagel (2016) and the standard one-period Euler condition that depends on market prices. The GPME is unique among PE performance evaluation measures in that it is well grounded in asset pricing theory. We highlight that it represents a first order condition for optimal asset allocation and is equivalent to the net present value (NPV) of cash flows over the life of the investment. We illustrate that the implicit beta in the discount factor for GPME, however, is a cash flow yield beta

\footnotetext{
${ }^{1}$ While secondary market liquidity was limited in the nascent years of the secondary market, liquidity has grown substantially over the past decade.
} 
with the growth in investor marginal utility. In contrast, the standard Euler equation represents the one-period NPV using market prices, in which the implicit beta is a total return beta. We further show that if discount rates vary over time, then GPME generally reflects the unconditional oneperiod NPV plus a term representing PE discount rate risk: the covariance of PE discount rates with the growth in investor marginal utility. Such risk impacts the one-period NPV, but not the GPME.

We then turn to the second and third questions mentioned above to investigate variation in private equity discount rates and determine the impact of this form of discount rate risk on performance evaluation measures. To do so we use data obtained from a large intermediary in this market to evaluate the risk and return of private equity funds in a similar manner to the way in which investors regularly use public equity markets to understand the risk and return of publicly traded companies. Using these data, we construct market-based indices for buyout funds. By comparing the performance of our indices with that of standard NAV-based indices and an index based on listed private equity companies, we obtain new insights about the performance of private equity. In contrast to much of the existing literature, our transaction-based indices suggest that buyout funds do not outperform public markets on a risk-adjusted basis. ${ }^{2}$

A difficulty in constructing an index using our secondary market data for private equity is accounting for the facts that no fund trades in every period, and many funds do not trade at all. In the subsample of funds that could be matched with cash flow data from the Preqin database, there are 839 buyout transactions for 287 unique funds from 2006 through 2018, implying that the average fund trades 2.9 times in our sample, conditional trading at all. Moreover, the funds that do trade are not randomly chosen, and sample selection could potentially affect inferences from empirical analysis if not controlled for econometrically.

We explicitly account for the possibility that specific types of funds may trade more often than others by using the approach of Heckman (1979). On a large sample of buyout funds, we estimate the parameters of an econometric model using observed transaction prices. We use this model each period to create an inferred price for every fund in our population every period, including those that do not transact. We then construct our transactions-based index from these

\footnotetext{
${ }^{2}$ For example, current evidence suggests buyout funds outperform on a risk-adjusted basis (Higson and Stucke (2012), Harris, Jenkinson, and Kaplan (2014), and Robinson and Sensoy (2016))..
} 
inferred prices. ${ }^{3}$ When estimating index parameters, we account for non-synchronicity in prices we observe using the approach of Dimson (1979).

We estimate the beta of our main secondary market PE index to be 1.79 As emphasized by Axelson, Sorensen and Strömberg (2014), the return on a buyout fund is essentially the return on a portfolio of highly levered firms. If the portfolio firms prior to the buyout have unlevered betas around 1, doubling their leverage, as was typically done in buyouts during our sample period (2006-2018), should lead to a portfolio beta around 2. ${ }^{4}$ The benchmark beta of 1 in this calculation is a total return beta, and produces a total return beta for PE consistent with the total return betas we estimate using our indices. In contrast, others in the literature have measured beta for PE using cash flows data only, an approach which is likely to overlook the influence of variation in discount rates on betas. For our main index we document an alpha of $-2 \%$ annually. This also contrasts with the vast majority of the literature that in general finds that buyout funds outperform on a riskadjusted basis.

We find that log book-to-market ratios vary considerably for our secondary market PE index. Using regressions motivated by the Campbell Shiller (1988) identity, we find that all variation in log book-to-market ratios for private equity can be explained by variation in market discount rates. A similar phenomenon has been documented for other asset classes including public equities, treasuries, credit, foreign exchange, and sovereign debt. ${ }^{5}$ From these regressions we find the standard deviation of long-run private equity discount rates to be about 0.36. Cochrane (2011) estimates the standard deviation of discount rates at similar horizons for public equity to be 0.29 . Our estimates suggest that discount rates for private equity vary about as much, if not somewhat more, than those for public equity. In contrast, the implicit long-run discount rates in NAVs exhibit a standard deviation of about 0.10 . NAVs are too smooth, not only because they reflect stale information, but also because they fail to reflect variation in market PE discount rates.

In contrast to our index alpha, the GPME for funds in our main index is relatively large at about 0.27 , and is comparable to that of venture funds pre-1998, a period of strong performance for venture funds (Korteweg and Nagel (2016)). An explanation for the discrepancy we find

\footnotetext{
${ }^{3}$ Other indices based on secondary markets have also incorporated some type of interpolation to infer the prices of non-traded assets. Bond indices, for instance, often employ "matrix pricing" to infer the prices of non-traded bonds.

${ }^{4}$ This calculation assumes that the debt beta equals zero. In fact, estimates of buyout debt betas are positive, which would lead the fund-level beta in this example to be less than 2 (see Kaplan and Stein (1990)).

${ }^{5}$ Cochrane (2011) provides a summary of the literature.
} 
between the GPME for funds in our main index, and the alpha of the index itself is that performance measures based on secondary market prices, such as alpha, depend on variation in market discount rates for PE while performance measures based on cash flows do not. Other reasons, however, might explain the difference in these results that are specific to PE secondary markets, transaction costs, or the manner in which we construct our PE secondary market indices. To rule out such explanations, we evaluate a group of investments in public equities where valuations and portfolio construction are transparent, and where transaction costs are relatively low. We construct the cash flows for a series of synthetic funds that invest in size-decile portfolios of public equities. For these synthetic funds we find the estimated GPMEs to be large and statistically significant, but standard CAPM alphas to be slightly negative. These results help bridge the divide between the large estimated GPME for funds in our index and the estimated index alpha that is slightly negative, and suggest that the gap is not driven by explanations specific to our index or PE secondary markets. Rather, the divide appears to be differences in how these performance measures account for PE discount rate risk.

To address the fourth question presented above, we provide some discussion that considers the kind of investor for whom PE secondary market prices are relevant. Many PE investors do not often engage in PE secondary markets and simply collect the cash flows. It is similarly common for investors who buy corporate bonds to avoid trading in secondary markets and collect the coupons. Many bond investors, however, regularly optimize and rebalance their portfolios in markets for credit and interest-rate swaps, which are facilitated by the existence of secondary market prices for bonds. Just as the factor exposures of coupon or interest payments do not capture the full risk exposure of bond investors, the factor exposures of PE cash flows do not capture the full risk exposure of PE investors with a variety of objectives. We further add to this discussion below.

Finally, what role do liquidity discounts play in our results? The returns of all asset classes in secondary markets are influenced to some degree by transaction costs. In secondary markets for private equity, most transaction costs appear to be borne by sellers. Buyers earn a small premium as market makers if positions are held to the end of a fund's life (Nadauld, Sensoy, Vorkink, and Weisbach, (2019), NSVW hereafter). Our index returns reflect returns from buying and selling at secondary market prices. To the extent that buyers earn a premium for market making, this premium is largely canceled out when the position is sold three months later. 
Our paper is organized as follows. In Section 2 we discuss various approaches the literature has taken to measure risk in private equity. Section 3 provides a conceptual framework motivating our study of discount rate risk vs cash flow risk. Section 4 describes the methodology used to create a private equity index using secondary market prices. Section 5 summarizes our data. Section 6 presents estimates of the model used to create the index and subsequent PE alphas, betas, and other performance metrics arising from the index. Section 7 describes empirical measures of discount rate risk $\mathrm{n}$ private equity and its influence on standard performance measures. Section 8 concludes.

\section{Prior Work Measuring Private Equity Risk and Return}

For most asset classes, investors rely on secondary market transaction-based indices to measure performance, in which case risk can be appropriately characterized as the covariance of total return with a relevant stochastic discount factor. Because such secondary markets did not exist for many years in private equity, alternative approaches were developed to measure and assess risk and return in this market. Korteweg (2018) provides a thorough survey of the PE performance literature. Here we review a few highlights. We classify prior studies of PE investment performance into six groups which vary depending on the recommended approach.

First, a number of studies estimate the CAPM alpha and beta of private equity using book returns based on the net asset value specified by the general partner (see Anson (2007), Woodward (2009) and Ewens, Jones and Rhodes-Kropf (2013)). Because the portfolio companies often have no observable market price, marked values often do not reflect the most recent information in public markets. To accurately measure systematic risk, these authors project book returns on current and lagged market returns and then sum up the estimated coefficients to obtain an estimator for beta as in Dimson (1979). These studies find beta for buyout companies to be in the range of 0.70 to 1.0 with alphas ranging from $3.2 \%$ to $4.8 \%$ annualized.

A second group of studies evaluate private equity performance by estimating the public market equivalent, or PME, of Kaplan Schoar (2006) using cash flows paid to and received by limited partners. Recent studies that use net-of-fee fund-level cash flow data find the PME for buyout funds to be in the range of 1.19-1.23, suggesting that buyout funds outperform public equity markets even after adjusting for fees (see Higson and Stucke (2012), Harris, Jenkinson, and Kaplan (2014), and Robinson and Sensoy (2016)). Kortegweg and Nagel (2016) develop the GPME to 
relax restrictions on the stochastic discount factor implicit in the PME and study the performance of venture companies. ${ }^{6}$

A third group of studies evaluate PE performance by estimating factor alphas and betas from regressions of $\log$ IRR's on the contemporaneous IRRs of the public equity market and other factor portfolios. Most papers that take this approach estimate fund log IRRs from cash flows between private equity funds and their portfolio firms (see Frazoni, Nowark, and Philippou (2012) and Axelson, Sorensen, and Strömberg (2014).) These papers find buyout betas to be in the range of 0.90 to 2.4 with alphas in the range of $8.6 \%$ to $9.3 \%{ }^{7}$

A fourth group of studies evaluate the performance of private equity by creating mimicking portfolios of publicly traded securities that are similar to PE in terms of portfolio company characteristics (Groh and Gottschalg (2011) and Stafford (2017)). In a related approach, Gupta and Van Nieuwerburgh (2020)) create synthetic strips to match the cash flows paid to and from limited partners using a variety of exchange traded securities. The market prices of these strips cannot be observed and are evaluated using a no-arbitrage pricing model. These studies find buyout betas in the range of 1.4 to 1.8 and alphas in the range of $8.4 \%$ to $11.8 \%$ annualized.

A fifth group of studies develop methods to estimate PE buyout risks by imposing a model on systematic cash flow risks across funds and through time (Buchner and Stucke (2014), Driessen, Lin, and Phalippou (2011), and Ang, Chen, Goetzmann, and Phalippou (2018)). These papers find buyout betas in the range of 1.3 to 2.7 and alphas from $-4.8 \%$ to $4.5 \%$ annualized.

Finally, a sixth group of studies develop approaches to evaluate private equity based on the returns to publicly traded private equity securities (Jegadeesh, Kraussl, and Pollet (2015) and McCourt (2018)). These studies estimate betas for buyout funds to be in the range of 0.7 to 1.1 with alphas from $1.2 \%$ to $7.2 \%$ annualized.

Overall, the vast majority of evidence in the literature suggests that buyout funds tend to outperform on a risk-adjusted basis using data on PE cash flows. But valuation and performance

\footnotetext{
${ }^{6}$ Whereas the PME is the ratio of discounted distributions to discounted capital takedowns, the GPME is the difference, or NPV based on a stochastic discount factor. When capital calls are stochastic, asset pricing theory makes no clear predictions about the expected ratio because of a Jensen's inequality effect (see Kortegweg and Nagel (2016)). If we define the PME as discounted distributions minus contributions, then the GPME nests the PME with the SDF defined as the inverse public market return.

${ }^{7}$ In contrast to our work, studies based on cash flows between private equity funds and their portfolio firms estimate risk and return gross of fees. Carried interest, which is similar to a short call position from the perspective of the investor, causes the net-of-fee beta to be lower than the gross-of-fee beta if the fund itself covaries positively with the market. Kaplan and Schoar (2005) run similar regressions using IRRs estimated from cash flows paid to and received by limited partners.
} 
measurement based on cash flow data can, in general, only account for cash-flow risk exposures. Factor exposures measured in much of the existing work are "cash flow betas" that measure the covariance between the stochastic discount factor (SDF) and cash flows of the underlying PE investment. ${ }^{8}$ These estimates miss risk exposures coming from co-movement of the SDF with valuations associated with changes in PE discount rates. Without data on actual secondary market prices, it is impossible to understand the magnitude of this risk and the impact it may have on PE performance and standard metrics such as alpha and beta.

Some studies evaluate PE performance using either PE NAVs or exchange traded asset returns. The well-known excessive "smoothness" of NAVs has been attributed to the use of stale information by general partners. But the impact of stale information can be accounted for using standard statistical techniques such as those proposed by Dimson (1979). Any excess smoothness in NAVs after appropriately accounting for the use of stale information should emerge from different causes. We provide evidence that variation in NAVs fails to account for dynamics in market PE discount rates.

To the extent that discount rates are correlated, market prices of other exchange traded products could reflect some of the variation in PE discount rates, but other assets are clearly not perfect substitutes for PE. The marginal investor in private equity is likely to differ from the marginal investor for other asset classes, such as public stocks, in terms of preferences and sophistication. Dynamics in sentiment and risk aversion and their impact on discount rates may differ for private equity than for other assets classes. Moreover, the organizational structure of private equity may also generate unique properties in private equity risk.

Listed private equity securities, in particular, mostly represent publicly traded funds of funds and the equity shares of general partners who have listed publicly. Their returns are likely to be correlated with those received by limited partner returns in private equity funds but are also likely to be different for at least four reasons. First, the cash flows of publicly traded securities of private equity firms reflect cash flows of the general partners, whose claim is the present value of future fees and carried interest earned by the fund, rather than the cash flows of the limited partner

\footnotetext{
${ }^{8}$ They are cash flow betas in a different sense than in Campbell and Vuolantenaho (2004). These authors define the cash flow beta as the covariance between the total return of the asset being evaluated and the component of the SDF attributable to news about aggregate cash flows. The factor exposures and SDF covariances behind performance measures using PE cash flows in the existing PE literature represent covariances between the cash flows of the asset being evaluated and the total $S D F$.
} 
in a particular fund. Second, large, publicly traded buyout firms such as Blackrock and KKR hold a variety of investments other than private equity, including hedge funds, real estate, advisory services, etc. Third, some of the publicly traded private equity funds are funds of funds that charge an extra layer of fees (that varies with performance) in addition to the fee collected by the managers of the unlisted funds in which funds of funds invest. Finally, there is potential for sample selection in the types of funds that choose to list public shares.

\section{Performance Evaluation Based on Cash Flows versus Transaction Prices}

In this section we present a conceptual framework that connects cash-flow measures of performance with traditional performance measures in asset pricing. In doing so, we characterize the way in which an investor should use information in secondary market prices to make optimal capital allocation decisions.

\subsection{Two First-Order Conditions}

The standard Euler equation that defines optimal allocation to asset $i$ is given by

$$
E_{t}\left[M_{t: t+1}\left(X_{i, t+1}+p_{i, t+1}\right)\right]-p_{i, t}=0
$$

where $X_{i, t+1}$ represents cash flows paid by the asset at time $t+1, p_{i, t+1}$ is the value of the asset at time $t+1$, and $M_{t: t+j}$ represents the investor's discounted growth in marginal utility from $t$ to $t+j$,

$$
M_{t: t+j}=\delta^{j} \frac{u^{\prime}\left(c_{t+j}\right)}{u^{\prime}\left(c_{t}\right)}
$$

where $\delta$ is the subjective discount factor. After scaling by $p_{t}$ the left side of (1) is alpha relative to $M_{t: t+j}$. Numerous asset pricing studies test the null that unconditional alpha is zero relative to various specifications for $M_{t: t+j}$. When the objective is asset allocation and evaluating the expected welfare gains from tilting towards an investment the investor need not be the representative investor, and although we follow Korteweg and Nagel (2016) in referring to $M_{t: t+j}$ as the investor's stochastic discount factor (SDF), $M_{t: t+j}$ is not necessarily an equilibrium pricing kernel. The investor's SDF is typically expressed as a negative function of the return on the investor's portfolio. This interpretation of the Euler condition given in (1) is analogous to the standard interpretation of performance measures in the mutual fund and hedge fund literatures.

Equation (1) characterizes optimal allocation to the asset for both a one-period investor, and a long-term investor that maximizes expected utility over multiple periods and expects to 
rebalance optimally in future periods. To highlight this point and connect equation (1) to cashflow measures of performance in private equity, consider a long-term individual investor who is able to invest in private equity fund $i$ that makes capital calls and provides distributions. At time $t$ the investor chooses the number of additional units of private equity to acquire, where each unit provides a series of stochastic cash flows, $X_{i, t+j}$, that arrive at times $t+j$ for $j=1, \ldots T$, where $X_{i, t+j}$ can be positive, negative or zero. Assume the investor makes this choice to maximize the expected utility of consumption over $T$ periods,

$$
U_{t}=E_{t} \sum_{j=0}^{T-t} \delta^{j} u\left(c_{t+j}\right),
$$

where, as usual, $u(\cdot)$ represents utility of consumption. The individual investor's first order condition, subject to standard budget constraints, is

$$
E_{t} \sum_{j=1}^{T-t} X_{i, t+j} M_{t: t+j}-p_{i, t}=0
$$

The price of an additional PE unit, $p_{i, t}$ is zero if the first capital call is made after time $t$. The left side of equation (4) is the expected GPME developed by Korteweg and Nagel (2016), conditional on time $t$ information. For clarity, we refer to the left side of (4) simply as "GPME". If GPME is positive, then the investor can increase expected utility by acquiring additional private equity units, which lowers the covariance between $M_{t: t+j}$ and $X_{i, t+j}$. To maximize expected utility, the individual investor acquires additional units until (4) holds. Korteweg and Nagel (2016) test the null hypothesis that (4) is zero for a sample of venture capital funds using an SDF that is a negative function of the return on the public stock market portfolio.

If the individual investor optimizes via secondary markets next period such that (4) holds at time $t+1$ then the first order condition given by (4) collapses to the standard Euler equation given by (1). The Euler condition recognizes that the investment decision is dynamic, and that future secondary market prices convey information about how the investor's portfolio and marginal utility (and their relation to future cash flows) will likely evolve over time as the investor optimally responds to changing market conditions.

Rebalancing frequency in the real world is endogenously determined by investor objectives and transaction costs. The most salient of such costs may be the liquidity discount. As a sellermotivated market, buyers make a small premium for providing liquidity to sellers. NSVW (2019) 
document that these costs amount to a 5\% annualized performance loss for the seller and a $5 \%$ performance gain for the buyer on average. In a round-trip transaction these gains and losses mostly cancel out. Other costs, however, can still prevent an LP from directly engaging in PE secondary markets. For example, an LP can potentially harm relationships with GPs that may preclude the LP from future deals if the LP sells PE stakes in the secondary market. LPs also face costs to acquire sufficient expertise and/or key relationships to overcome asymmetric information problems in these markets. When investors hold assets with high transaction costs, they generally optimize their portfolios dynamically using correlated assets with greater liquidity. For example, swap markets exist to enable corporate bond investors to hedge and rebalance their exposure to interest-rate and credit risk. In this section we assume the existence of an individual investor who chooses to rebalance each period, and highlight the relationship between the GPME and Euler equations for such an investor.

The left side of the Euler condition given in (1) is the one-period net present value (NPV), expressed in terms of a stochastic discount factor. Notationally we refer to the one-period NPV as $\pi_{i, t}$. We can rearrange the terms of (1) to express NPV in terms of a deterministic discount factor, a known constant as of time $t$, that is a linear function of the total return beta with the SDF. To see how, note that:

$$
\begin{aligned}
\pi_{i, t} & \equiv E_{t}\left[M_{t: t+1}\left(X_{i, t+1}+p_{i, t+1}\right)\right]-p_{i, t} \\
& =\frac{E_{t}\left[X_{i, t+1}+p_{i, t+1}\right]}{R_{f, t: t+1}+\lambda_{t} \beta_{i t}}-p_{i, t}
\end{aligned}
$$

where $\lambda_{t}=\operatorname{Var}_{t}\left(M_{t: t+1}\right) / E_{t}\left[M_{t: t+1}\right], R_{f, t: t+j}$ denotes the risk-free rate from $t$ to $t+j$ and $\beta_{i, t}$ is the beta of the total return for the asset. ${ }^{9}$ In particular if $R_{i, t+1}=\left(X_{i, t+1}+p_{i, t+1}\right) /\left(p_{i, t}+\pi_{i, t}\right)$ denotes the total return from purchasing at the zero-NPV price then,

$$
\beta_{i, t}=\frac{\operatorname{Cov}_{t}\left(R_{i, t+1}, M_{i, t: t+1}\right)}{\operatorname{Var}_{t}\left[M_{t: t+1}\right]}
$$

In contrast, deterministic discount factors implied by GPME are linear functions of cashflow-yield betas with the SDF. To see this, divide up the cash flows paid by the asset into

\footnotetext{
${ }^{9}$ Here we assume the risk-free asset represents a zero NPV investment so that $R_{f, t: t+1}=1 / E_{t}\left[M_{t: t+1}\right]$. If $Z_{i, t}=$ $X_{i, t+1}+p_{i, t+1}$, then $E_{t}\left[M_{t: t+1} Z_{i, t+1}\right]=E_{t}\left(M_{t: t+1}\right) E_{t}\left(Z_{i, t}\right)+\operatorname{Cov}_{t}\left(M_{t: t+1}, Z_{i, t+1}\right)$ which implies $E_{t}\left(Z_{i, t+1}\right)=$ $\left[E_{t}\left(M_{t: t+1} Z_{i, t+1}\right)-\operatorname{Cov}_{t}\left(M_{t: t+1}, Z_{i, t+1}\right)\right] / E_{t}\left(M_{t: t+1}\right)$. Dividing $E_{t}\left(Z_{i, t+1}\right)$ by the right side of the previous equation and multiplying both sides by $E_{t}\left(M_{t: t+1} Z_{i, t+1}\right)$ implies $E_{t}\left(M_{t: t+1} Z_{i, t+1}\right)=E_{t}\left[Z_{i, t}\right] /\left[R_{f, t: t+1}+\lambda_{t} \beta_{i t}\right]$.
} 
dividend strips, and let $P V_{i, t(t+j)}$ denote the present value of dividend strip $t+j$ that pays cash flow $X_{i, t+j}$ so that the GPME is equal to the sum of $P V_{i, t(t+j)}$ over all $j$. The implied betas in GPME can be understood by noting that

$$
\begin{aligned}
P V_{i, t(t+j)} & \equiv E_{t}\left[M_{t: t+j} X_{i, t+j}\right] \\
& =\frac{E_{t}\left[X_{i, t+j}\right]}{R_{f, t: t+j}+\gamma_{t(t+j)} \beta_{i, t(t+j)}^{x}}
\end{aligned}
$$

where $\gamma_{t(t+j)}=\operatorname{Var}_{t}\left(M_{t: t+j}\right) / E_{t}\left[M_{t: t+j}\right]$, and $\beta_{i, t(t+j)}^{x}$ represents the beta of the asset's cash-flow yield. ${ }^{10}$ In particular, if we let $Y_{i, t+j}=X_{i, t+j} / P V_{i, t(t+j)}$ represent the cash flow yield based on the zero-NPV market value for dividend strip $t+j$, then

$$
\beta_{i, t(t+j)}^{x}=\frac{\operatorname{Cov}_{t}\left(Y_{i, t+j}, M_{i, t: t+1}\right)}{\operatorname{Var}_{t}\left[M_{t: t+1}\right]}
$$

Equations (5) and (7) highlight that performance measures such as one-period NPV and alpha account for covariation between prices and the SDF, while other measures based on cash flows do not. Under what conditions do these differences matter? In the special case that the SDF of the individual investor represents an equilibrium pricing kernel, both the one-period NPV and the GPME are equal to zero. Otherwise, each performance measure may point to a different optimal allocation strategy. For example, it is possible at time $t$ for NPV to be zero even though the GPME is positive.

To see this, if the final cash flow is paid out at time $t=T$, then $p_{T}=0$ and the one-period NPV at time $T-1$ is given by

$$
\pi_{i, T-1}=E_{T-1}\left[M_{T-1: T} X_{T}\right]-p_{T-1} .
$$

If we solve (9) for $p_{T-1}$, substitute this definition of $p_{T-1}$ into $\pi_{i, T-2}$, and continue in like manner iterating backwards, we can express the GPME for fund $i$ in terms of one-period NPVs instead of cash flows,

$$
E_{t}\left[G P M E_{i}\right]=\sum_{j=0}^{T-t-1} E_{t}\left[M_{t: t+j} \pi_{i, t+j}\right] .
$$

Equation (10) is a simple accounting identity that shows GPME is equivalent to the sum of stochastically discounted one-period NPVs over the life of the fund based on the individual

\footnotetext{
${ }^{10} \mathrm{We}$ again assume that the risk-free asset is zero NPV so that $R_{f, t: t+j}=1 / E_{t}\left[M_{t: t+j}\right]$. The rest of the derivation closely follows footnote 10 .
} 
investor's SDF. Relative to the GPME defined in (4), we essentially add the stochastically discounted price each period, $E_{t}\left[M_{t: t+j} p_{i, t+j}\right]$, and subtract it out in the subsequent period to arrive at (10).

The terms of equation (10) can be rearranged as

$$
E_{t}\left[G P M E_{i}\right]=\sum_{j=0}^{T-t-1} E_{t}\left[\pi_{i, t+j}\right] E_{t}\left[M_{t: t+j}\right]+\sum_{j=1}^{T-t-1} \operatorname{Cov}_{t}\left(M_{t: t+j}, \pi_{i, t+j}\right) .
$$

If the risk-free security represents a zero-NPV investment based on the investor's SDF, then $E_{t}\left[M_{t: t+j}\right]=1 / R_{f, t: t+j}$. The first summation on the right of (11) may therefore be interpreted as the risk-neutral discounted sum of expected one-period NPVs over the life of the fund, based on marginal utilities given the investor's current portfolio. If expected NPV is constant over the lifecycle of the fund, $E_{t}\left[\pi_{i, t+j}\right]=E_{t}\left[\pi_{i, t+k}\right]$ for any $j$ and $k$, then this first component may be considered a rough approximation of $T \times \mathrm{NPV}$, to the extent that risk-free rates are close to one.

To provide an intuitive interpretation for the second summation on the right of (11), suppose an equilibrium pricing kernel exists given by the SDF of the representative investor, $M_{R, t: t+j}$, such that

$$
E_{t}\left[M_{R, t: t+1}\left(X_{i, t+1}+p_{i, t+1}\right)\right]-p_{i, t}=0 .
$$

If the risk-free security represents a zero-NPV investment relative to both SDFs, then

$$
\pi_{i, t}=\operatorname{Cov}_{t}\left[M_{t: t+1}, X_{i, t+1}+p_{i, t+1}\right]-\operatorname{Cov}_{t}\left[M_{R, t: t+1}, X_{i, t+1}+p_{i, t+1}\right] .
$$

Equation (13) illustrates that one-period NPV from the perspective of the investor can naturally arise, even when prices are in equilibrium, from differences in how future payoffs are discounted. Such differences may naturally reflect, for example, a missing factor in $M_{t: t+1}$ relative to $M_{R, t: t+1}$. For example, it is standard in asset management to evaluate the performance of investments based on their ability to nudge the Sharpe ratio of the market portfolio higher as indicated by the CAPM alpha, even though the CAPM does not represent an equilibrium pricing model.

From (13) we can see that when $\pi_{i, t}$ is high, the representative investor "excessively discounts" the future PE payoff relative to the preferences of the individual investor. ${ }^{11} \mathrm{We}$ therefore interpret the second summation term in equation (11) as a unique measure of PE discount rate risk, which captures the covariance between the investor's SDF and movements in discount

${ }^{11}$ In the marginal utility framework, a low negative covariance with $M_{t: t+j}^{R}$ denotes a high discount rate. 
rates. When this covariance is positive, prices tend to fall right when the investor's marginal utility is high. Such positive covariance lowers the one-period NPV, but not the GPME. To relate the GPME to the one-period NPV, therefore, this extra term must be added on the right of equation (11).

The covariance term on the right of (11) is non-zero only if one-period NPVs (or conditional alphas) are stochastic. When this covariance is positive, GPME may be positive even though the expected one-period NPV is zero. Even when an investment looks like a great deal based on cash flows, for example, expected utility can sometimes be enhanced by choosing to wait for an opportunity to get in on the investment when market discount rates are relatively high, prices are low, and the one-period NPV is positive. By getting in immediately, the investor is simply acquiring a position that loses market value right when capital resources are needed the most.

\subsection{For Whom are Secondary Market Prices Relevant?}

Because cash-flow data are readily available, it is easier to estimate cash-flow based measures of performance than others. Given that data on secondary market prices are available however, investors can achieve greater ability to optimally allocate capital to PE and other asset classes. Besides benefitting investors that engage in PE secondary markets to optimally rebalance, information in PE secondary market prices can also help investors that typically buy and hold their PE stakes to make better capital allocation decisions.

As discussed above, transaction costs and objectives endogenously determine optimal rebalancing frequency. (See, for example, Dimmock, Wang and Yang (2019)). Private equity investors who face large transaction costs may optimally hold their private equity positions for several periods without rebalancing, and simply collect the cash flows. It is similarly common for investors who buy corporate bonds to avoid trading in secondary markets and collect the coupons,

and for banks to hold loans on their balance sheets and collect interest payments. Secondary markets for bonds and bank loans exist, but they are rather illiquid. Banks and corporate bond investors, however, still regularly optimize and rebalance their portfolios in relatively deep, liquid markets for credit and interest-rate swaps. Observing movements in secondary market prices for corporate bonds and securitized bank loans, regardless of whether such movements are driven by variation in discount rates or news about future cash flows, enables such investors to know how to optimally rebalance. Just as factor exposures and SDF covariances relative to coupon payments do not capture the full risk exposure of corporate bond investors, factor exposures and SDF 
covariances relative to PE cash flows do not capture the full risk exposure of PE investors. Secondary market PE indices can enable PE investors to increase expected utility by trading in correlated market products, even if secondary market transaction costs cause investors to generally hold the PE position until liquidation.

Moreover, investors that assign a zero probability to states of the world in which it is optimal to rebalance in secondary markets after transaction costs risk misallocating their capital. States of the world exist in which even investors that face high transaction costs will find it optimal to rebalance their actual PE holdings. For example, during the 2008 Financial Crisis some normally buy-and-hold private equity investors were hit with severe losses and found it optimal to sell their $P E$ stakes in secondary markets to avoid liquidity shortfalls from impending capital calls. Such conditions represent particularly bad states of the world in which marginal utility is especially high (states with high risk-neutral probability), making them among the most important considerations when allocating capital to both private equity and other correlated asset classes. Ignoring such states can lead to misallocations, unintended correlations, and unwanted risk exposures. A better understanding of PE market valuations and their relation to risk factors can help PE investors avoid liquidity shortfalls, smooth consumption, and hedge against states in which assets with high transaction costs must be sold.

\section{Creating an Index}

Relative to creating indices on exchange-traded securities such as stocks, creating a marketbased private equity index is challenging because every fund does not transact every period and those that do transact are not selected randomly. Our approach to creating an index of private equity returns relies on three key components: two first-order approximations and the estimation of a Heckman (1979) sample selection model. We first lay out the basic intuition of our approach, and then provide additional details.

\subsection{Intuition of Index Construction}

To construct an index of returns, suppose we observe quarterly returns for $N$ assets, $\tilde{r}_{1}, \ldots, \tilde{r}_{N}$. The equal-weighted portfolio return for the quarter, $\tilde{r}_{p}$, is the cross-sectional average,

$$
\tilde{r}_{p}=\frac{1}{N} \sum_{i=1}^{N} \tilde{r}_{i} .
$$

If we project returns on a set of characteristics, $\boldsymbol{x}_{\boldsymbol{i}}$, that includes an intercept, 


$$
\tilde{r}_{i}=\boldsymbol{x}_{\boldsymbol{i}}^{\prime} \boldsymbol{b}+e_{i}
$$

then we can recover the true realized equal-weighted portfolio return as,

$$
\tilde{r}_{p}=\overline{\boldsymbol{x}}^{\prime} \boldsymbol{b}
$$

where $\overline{\boldsymbol{x}}$ is the cross-sectional average value of $\boldsymbol{x}_{\boldsymbol{i}}$ across all $N$ funds. In the linear projection given by equation (16), both $e_{i}$ and $x_{i} e_{i}$ average out exactly to zero across the $N$ funds in our population. These residual properties hold, and we can recover the true realized portfolio return, for any $\boldsymbol{x}_{\boldsymbol{i}}$ we choose, provided that $\boldsymbol{x}_{\boldsymbol{i}}$ contains an intercept. The purpose of equations (16) and (17) is to calculate the realized portfolio return, not to estimate the parameters of a model we hope is relevant outside our population of $N$ funds. The standard approach to calculate realized portfolio returns given by equation (15), in fact, represents a special case of (16) with $\boldsymbol{x}_{\boldsymbol{i}}$ equal to one.

We do not observe $\tilde{r}_{i}$ for the full population of $N$ funds, but only for a sample of funds in a given quarter. If we were to estimate $\boldsymbol{b}$ using only the observations for which we have data on both $\tilde{r}_{i}$ and $\boldsymbol{x}_{\boldsymbol{i}}$ then the OLS estimate of $\boldsymbol{b}$ will be inconsistent unless the subset of funds that transact are chosen randomly. NVSW (2019) document, however, that larger and more established funds are more likely to transact in this market, and hence, the funds that do transact do not appear to be randomly selected.

We therefore use a selection model to consistently estimate $\boldsymbol{b}$, based on the approach of Heckman (1979). While we do not observe $\tilde{r}_{i}$ for every fund, we do observe $\boldsymbol{x}_{\boldsymbol{i}}$ for every fund. Using our estimate of $\boldsymbol{b}$ we calculate the index return as the average predicted return each quarter as in (17) using all $N$ funds in the population. We thus obtain consistent estimates of index returns each quarter based on the private equity secondary-market transactions we observe.

\subsection{Inferring Index Returns from Book-to-Market Ratios}

While the preceding discussion outlines the basic approach to index construction, we now explain further details. Funds do not often transact in adjacent quarters, and as such, the number of individual fund transactions and market value is much greater than the number of observed individual quarterly fund returns. We therefore infer index returns from observed log book-tomarket ratios in adjacent quarters using the Campbell Shiller (1988) identity. Doing so enables us to take advantage of all transactions in our sample, regardless of whether the same funds transact in adjacent quarters or not. Besides enabling us to estimate returns for our private equity index, our approach is convenient for understanding variation in PE discount rates, since all variation in 
log book-to-market ratios must be associated with either variation in market discount rates, variation in book-discount rates, or variation in future book-to-market ratios.

Let the quarterly $\log$ portfolio market return for $P E$ fund $i$ from $t$ to $t+1$ be defined as

$$
r_{i, t+1}=\ln \left(\frac{P_{i, t+1}+X_{i, t+1}}{P_{i, t}}\right),
$$

where $P_{i, t+1}$ is the market value of the fund at time $t+1$, and $X_{i, t+1}$ represents total distributions minus capital calls for the portfolio from $t$ to $t+1 .^{12}$ Similarly, define the log-book return based on net asset values as

$$
n_{i, t+1}=\ln \left(\frac{N A V_{i, t+1}+X_{i, t+1}}{N A V_{i, t}}\right),
$$

where $N A V_{i, t+1}$ is the net asset value (book value) of the fund at time $t+1$. Our approach relies on two first-order approximations. The first is similar to an approximation of Vuolteenaho (2002) based on the Campbell Shiller (1988) identity and is further developed in Appendix A. This approximation provides a natural approach to adjust book returns to reflect market returns,

$$
r_{i, t+1}=n_{i, t+1}-\rho_{i, t+1} \theta_{i, t+1}+\theta_{i, t}
$$

where $\theta_{i, t}$ is the-log book-to-market ratio of the fund,

$$
\theta_{i t}=\ln \left(N A V_{i, t}\right)-\ln \left(P_{i, t}\right),
$$

and $\rho_{i, t+1}$ is an approximation parameter that can take on one of three values. If $X_{i, t+1}$ is positive (negative) then $\rho_{i, t+1}$ is slightly below (above) one. When $X_{i, t+1}$ is zero, then $\rho_{i, t+1}$ is identical to one and (20) holds exactly (See Appendix A for further details). Book values are likely to be among the most informative variables that we can observe regarding the future cash flows of the fund. Since we observe book-returns for every fund in our index each period, our market-based returns, $r_{i, t+1}$, contain all pricing information embedded in book values. The adjustment $-\rho_{i, t+1} \theta_{i, t+1}+\theta_{i, t}$ accounts for any omitted cash flow or discount rate news omitted in the book return relevant for the market return.

To aggregate individual fund returns to index returns, we rely on a second first-order approximation in which the average log return is approximately the log average return (see Appendix B). We cannot consistently estimate $\theta_{i, t}$ for funds that are missing given a set of characteristics, $\boldsymbol{x}_{\boldsymbol{i}}$, only $E\left[\theta_{i, t} \mid \boldsymbol{x}_{\boldsymbol{i} t}\right]$. We can, however, consistently estimate the cross-sectional

\footnotetext{
${ }^{12}$ When merging cash-flow data with market values we normalize to a \$1 commitment.
} 
average value of the log return each quarter, even if $\theta_{i, t}$ is missing for some funds. Intuitively, the true residual vanishes in the average.

To illustrate, suppose that we do observe $\theta_{i t}$ and a set of characteristics, $\boldsymbol{x}_{\boldsymbol{i t}}$, across all funds in each quarter. If we project $\theta_{i t}$ on a panel of characteristics, $\boldsymbol{x}_{i t}$, that includes time fixedeffects,

$$
\theta_{i t}=\boldsymbol{x}_{i t}^{\prime} \boldsymbol{b}+e_{i t}
$$

then we can recover the true average value of $\theta_{i t}$ in each quarter as

$$
\bar{\theta}_{i t}=\overline{\boldsymbol{x}}_{\boldsymbol{t}}{ }^{\prime} \boldsymbol{b},
$$

for any choice of $\boldsymbol{x}_{\boldsymbol{i}}$, where $\overline{\boldsymbol{x}}_{\boldsymbol{t}}$ denotes the average value of $\boldsymbol{x}_{\boldsymbol{i}}$ across funds in quarter $t$. Since we do not observe $\theta_{i, t}$ for all funds, we consistently estimate $\boldsymbol{b}$ under the model specification and assumptions of Heckman (1979). Section 4.3 below provides additional details. Let $\boldsymbol{b}^{*}$ represent a consistent estimate of $\boldsymbol{b}$, and define $\hat{r}_{i, t+1}$ as

$$
\hat{r}_{i, t+1}=n_{i, t+1}-\rho_{i, t+1} \boldsymbol{x}_{\boldsymbol{i} t+\mathbf{1}}^{\prime} \boldsymbol{b}^{*}+\boldsymbol{x}_{\boldsymbol{i t}}^{\prime} \boldsymbol{b}^{*}
$$

While we do not observe $\theta_{i t}$ for every fund in our index, we $d o$ observe $n_{i, t+1}, \boldsymbol{x}_{\boldsymbol{i t}+\mathbf{1}}^{\prime}$, and $\rho_{i, t+1}$ for the full population. Given our consistent estimate, $\boldsymbol{b}^{*}$, it then follows that the cross-sectional average value of $\hat{r}_{i, t+1}$ across funds in each quarter is a consistent estimate of $\bar{r}_{t+1}$, the average value of $r_{i, t+1}$ as defined in (20), representing the log return for the index. ${ }^{13}$

\subsection{Two-Step Heckman Approach}

To estimate $\boldsymbol{b}$ in (22) we follow the two-step approach of Heckman (1979). In the first step we estimate the parameters of a selection equation,

$$
y_{i t}=1\left[z_{i t}^{\prime} \boldsymbol{c}+u_{i t}>0\right]
$$

where $y_{i t}$ is a dummy variable that equals 1 when fund $i$ transacts at time $t$, and $\boldsymbol{z}_{\boldsymbol{i t}}$ represents a vector of fund characteristics observable across all funds in the index. A consistent estimator of the parameter vector $\boldsymbol{c}$ is available from a first-stage probit estimation of the selection equation using all funds in the portfolio. We then estimate the inverse Mills ratio, $\hat{\lambda}_{i t}$, as

$$
\hat{\lambda}_{i t}=\frac{\phi\left(\mathbf{z}_{i t}^{\prime} \boldsymbol{c}\right)}{\Phi\left(\mathbf{z}_{i t}^{\prime} \boldsymbol{c}\right)}
$$

\footnotetext{
${ }^{13}$ Note that $\rho_{i, t} \boldsymbol{x}_{\boldsymbol{i t}}^{\prime} \boldsymbol{b}=\rho_{i, t}\left(\theta_{\boldsymbol{i}, \boldsymbol{t}}-e_{i, t}\right)$ and that the approximation parameter, $\rho_{i, t}$, does vary slightly across funds in our application. To ensure that the average value of $\rho_{i, t} e_{i t}$ across funds in each quarter is zero we can appropriately include $\rho_{i, t}$ as one of the characteristics in $\boldsymbol{x}_{\boldsymbol{i t}}$. In practice, however, this makes very little difference in results.
} 
where $\phi(\cdot)$ is the normal distribution function and $\Phi(\cdot)$ is the cumulative normal distribution function. The second step is to estimate the equation specified in (22) by OLS after including $\hat{\lambda}_{i t}$ as an additional explanatory variable,

$$
\theta_{i t}=\boldsymbol{x}_{i t}^{\prime} \boldsymbol{b}+\hat{\lambda}_{i t} d+e_{i, t}
$$

The estimate of $\boldsymbol{b}$ in (27) will be consistent under the following four assumptions: (1) $\boldsymbol{z}_{\boldsymbol{i}}, \boldsymbol{x}_{\boldsymbol{i}}$, and $y_{i t}$ are observed for every fund in the portfolio and $\theta_{i t}$ is observed whenever $y_{i t}=1$, (2) $e_{i t}$ and $u_{i, t}$ are independent of both $\boldsymbol{z}_{\boldsymbol{i t}}$ and $\boldsymbol{x}_{\boldsymbol{i t}}$ with zero mean, $u_{i, t}$ is distributed $\operatorname{Normal}(0,1)$, and (4) $E\left(e_{i, t} \mid u_{i t}\right)=\delta u_{i t}$ where $\delta$ is a constant. (For example, see Wooldridge (2010), p. 803.) Robust identification that does not rely on assumption (3) requires an exclusion restriction: a variable in the selection equation that is uncorrelated with the book-to-market ratio. To help ensure that assumption (2) holds, all other characteristics in $\boldsymbol{z}_{\boldsymbol{i} \boldsymbol{t}}$ are sometimes included in $\boldsymbol{x}_{\boldsymbol{i t}}$ in practice.

Our approach differs somewhat from traditional hedonic techniques to estimate price indices (e.g., Gatzlaff and Haurin (1998) and Hwang, Quigley, and Woodward (2005)). The objective in estimating a traditional hedonic model is to understand price changes for a set of differentiated goods conditional on observed attributes such as quality or specific features. To mirror the typical portfolio definition of an index, we instead define a population of assets and seek to understand changes in the value of the aggregate population for which attributes, such as those related to expected cash flows and discount rates, change over time. An alternative approach to building price indices involves using repeat sales (e.g, Peng (2001)). Repeat sales are too infrequent in our transactions data to consider this approach.

\subsection{Explanatory Variables}

The key variables in the pricing equation are time-fixed effects, or state variables that represent time fixed effects, to ensure that the mean residual is zero within each quarter across all funds in the population. If funds were selected at random, time-fixed effects would be the only variables needed in our pricing equation to consistently estimate the average log book-to-market ratio across our population of funds. Because we are estimating the parameters of a sample selection model, any explanatory variables in the selection equation given in (25) that may be correlated with log book-to-market ratios, for whatever reason, can be useful to include in the pricing equation to help ensure that the pricing residual is independent of all explanatory variables in the selection equation (see assumption (2) in Section 4.3 above). Our primary objective is 
simply to estimate the average value of $\theta_{i, t}$, not to forecast the value of $\theta_{i, t}$ for individual funds or to understand how $\theta_{i, t}$ relates to specific characteristics. We demonstrate that our results are robust to the inclusion of either state variables or time fixed effects, with or without the additional fund-specific characteristics in the pricing equation in Appendix Table 1.

\subsection{Estimating Index Parameters}

We estimate index parameters (such as alphas and betas) for our private equity index. We compare our estimated parameters against those estimated for other indices, including a Preqin NAV-based index built using the same funds that are in our market price index, the Burgiss index which is also a NAV-based index, and the $S \& P$ Listed Private Equity Index.

So far, we have described a process to estimate the quarterly log return for our index. It is well-known that the intercept in a regression of excess log returns on excess market returns cannot be interpreted as alpha. A common solution is to estimate the intercept using annualized log returns, and then adjust under the assumption that log returns are normally distributed (for example, see Cochrane (2004) and Axelson, Sorenson, and Stromberg (2014)). To estimate parameters for the Preqin, Burgiss, and $S \& P$ indices mentioned above we use simple quarterly returns. To follow suit, we exponentiate our estimate of the quarterly index log return, the crosssectional average value of $\hat{r}_{i, t+1}$ given in (20), to arrive at a consistent estimate of the simple return for our index before calculating index parameters. We obtain similar results if we run regressions using excess log returns and adjust the intercept based on the normal assumption as others have done. These results are given in Panel A of Appendix Table 1.

The transactions in the private equity secondary market upon which we build our index are highly non-synchronous, occurring at various times throughout the quarter. Standard measures of alpha, beta, and volatility using non-synchronous data are in general, inconsistent. We therefore follow Dimson (1979) to estimate index betas by regressing returns on contemporaneous and lagged values of the market return, for an appropriate number of lags, and summing the slope coefficients. We estimate alpha as

$$
\alpha=\left(\bar{r}_{p, t+1}-\bar{r}_{f, t+1}\right)-\beta\left(\bar{r}_{m, t+1}-\bar{r}_{f, t+1}\right)
$$

where $\bar{r}_{p, t+1}$ represents our average estimated index return across quarters, $\bar{r}_{f, t+1}$ is the average return on short-term t-bills, $\bar{r}_{m, t+1}$ is the average public market return, and $\beta$ represents our Dimson 
adjusted beta. We obtain consistent estimates of volatility, Sharpe ratios, and correlation, under the model of Dimson (1979) as outlined in Appendix C.

\section{Data on Transactions in the Private Equity Secondary Market}

In this section we briefly describe the data and variables used to estimate the index. Our transaction data come from a large intermediary in the private equity secondary market, extending the data used by NSVW (2019). These data identify the fund that is sold, the total capital committed by the seller, the amount unfunded by the seller, the purchase price, and the transaction date for all transactions consummated through this intermediary from January of 2006 through December of 2018. We clean the data as detailed in Appendix D and pull the most recent transaction for each fund each calendar quarter for funds with a total commitment greater than $\$ 500$ million.

We obtain data on other fund characteristics, such as calls, distributions, $N A V$, fund $L P$ type, and size, from Preqin, from January 2006 through June of 2018, and clean these data as detailed in Appendix D. Preqin is built from a variety of sources including public filings and reports, submissions by GPs, and FOIA requests. While there are other data sets that may be more representative of the entire fund universe, Preqin is the only database that provides fund names, thus making it possible to merge in our secondary market transaction data.

Within each calendar quarter we sum all contributions and distributions for a given fund. We then merge transactions data with the Preqin sample, some of which is done by hand (see Appendix D for details). After this process, we end up with a sample of 596 funds for which we have fund-level data. We observe 839 transactions on 287 of these funds between the first quarter of 2006 and the second quarter of 2018.

We propose using eight explanatory variables in our selection equation: the log size of each fund, two age dummies, fund PME, the fraction of limited partners for each fund that are pension funds, and three state variables that proxy for quarter fixed-effects. For our main results we use state variables rather than quarter fixed effects to conserve power and because there is little economic insight to be gleaned from the coefficients on the fixed effects themselves. We demonstrate that our results are robust to this decision by replacing the three state variables with time fixed effects. We also illustrate that our results are robust to whether or not we include additional explanatory variables in the pricing equation along with state variables, or time fixedeffects. We report these results in Appendix Table 1. 
We measure size as total commitments by limited partners to the fund. The first age dummy equals one if the fund age (calculated in years relative to the vintage year) is less than 4 years, and zero otherwise. The second age dummy equals one if the fund age is greater than 9 years, and zero otherwise. We also use the Kaplan-Schoar (2005) PME for each fund-quarter, measured using cash flows from Preqin and using NAV at the end of the quarter as terminal value. The fraction of limited partners for each fund that are pension funds comes from Preqin.

Fund size and age are likely to be associated with asymmetric information about the fund or GP, and therefore the likelihood that a deal agreeable to both parties can be reached. Fund age is also directly related to the period over which fixed transaction costs can be amortized, suggesting that younger funds may be less likely to transact. PME captures information about the performance of funds that may be associated with supply and demand. Pension fund objectives are likely to differ from those of other investors making PE funds with high pension ownership less likely to be sold (further discussed below).

The three state variables we use include the log-value-weighted book-to-market ratio for small cap stocks, the TED spread, and a measure of total assets under management for the PE industry. We measure the small-cap book-to-market ratio using stocks with share code 10 and 11 in CRSP with less than $\$ 500$ million in market cap. We obtain the TED spread from the St. Louis Federal Reserve calculated as the spread between three-month LIBOR based on U.S. dollars and three-month treasury yields. We measure these two state variables at the end of the month prior to the fund's transaction date for funds that transact, and at the end of the second month of each quarter for funds that do not. Finally, we measure total assets under management, obtained from Bloomberg, at the end of the prior quarter and scale by the total number of firms in the U.S. with between 20 and 500 employees, obtained from the U.S. Census, measured at the end of the prior year.

We use the fraction of LPs invested in a fund that are pension funds, $P F_{i t}$, as an instrument. The investment objectives of pension funds differ from those of other investors: pension funds manage investment cash flows to match the timing of their liabilities but face unique regulatory incentives to refrain from dynamically hedging short-term liability risks (van Binsbergen and Brandt (2015)). As such, pension funds may be less likely to engage in PE secondary markets than other investors, such as a fund-of-funds. Consistent with this idea, NSVW (2019) document 
that empirically, pension funds sell their private equity stakes much less frequently than other investors.

To be a valid instrument, $P F_{i, t}$ must be uncorrelated with log book-to-market ratios after controlling for other observables. Book-to-market ratios are well known to predict stock returns, suggesting that they largely proxy for risk or mispricing in the cross section. Evidence on the relation between pension ownership and mispricing is somewhat mixed. Lerner, Schoar, and Wongsunwai (2007) document that pension funds outperform other LPs (other than endowments) in their PE reinvestment decisions, but their result does not replicate out of their 1990s sample, which does not overlap with our sample period (see Sensoy, Wang, and Weisbach (2014)). ${ }^{14}$

Table 1 reports summary statistics. Consistent with prior findings, funds on average transact at a discount relative to NAV (see NSVW (2019)). The overall average log-book-tomarket-ratio is 0.23 , roughly corresponding with a $20 \%$ discount $(1 / \exp (0.23)=0.80)$ and the median is 0.11 corresponding with a $10 \%$ discount.

The deviation between a fund's NAV and its market price will depend, in large part, on how the market discounts future expected cash flows relative to the GP. Hence, a trade for less than NAV is not necessarily reflective of a liquidity discount. The economic discount or premium at which a transaction occurs should be measured relative to the (unobservable) underlying value of the fund's assets, not the NAV. ${ }^{15}$

Funds that transact in the secondary market tend to be larger and older than average. The average log fund size for funds that transact is about 21.94 (corresponding with a size of $\$ 3.4$ billion) compared to an average log fund size for funds that do not transact of about 21.28 (corresponding with a size of $\$ 1.7$ billion). The average age of all transacting funds is 8.7 years, and 6.4 years for non-transacting funds. In addition, funds that transact display slightly higher average PMEs in the range of 1.16 compared to 1.13 for non-transacting funds. For the average fund in our sample, about $53 \%$ of the limited partners are pension funds, as indicated by the summary statistics on $P F_{i t}$.

\footnotetext{
${ }^{14}$ Others find that pension funds make poor investment decisions relative to other institutions (see Hochberg and Rauh (2012), and Andonov, Hochberg, and Rauh (2017)).

${ }^{15}$ NSVW (2019) develop this issue further. They argue that a second measure of a trade's discount relative to fundamental value is the difference in returns between buyers and sellers. If transactions always occurred at fundamental values and expected returns do not change over time, then buyer and seller expected returns should be approximately the same. Instead, these authors find that buyers of LP stakes outperform sellers, suggesting that, on average, transaction prices tend to be lower than fundamental values.
} 
Figure 1 reports the number of transactions per quarter for the full sample, of which there are 839 transactions. The figure highlights the rapid growth in the secondary market. The years 2017 and 2018 report almost five times the number of transactions as occurred in 2006 and 2007.

\section{Estimates of Secondary Market Based Private Equity Indices}

\subsection{Selection and Pricing Equations}

Table 2 reports estimates of the parameters for the selection and pricing equations specified in (25) and (27). Columns (1) through (4) report results for the Heckman model, while columns (5) and (6) report basic OLS estimates of the pricing equation without the inverse Mills ratio. For both approaches we calculate bootstrapped standard errors clustered by time that account for the inverse Mills ratio being a generated regressor.

The estimates presented in columns (1) and (2) suggest that a number of variates are associated with fund selection. First, our proposed pension fund instrument does predict selection into the transaction sample even after controlling for other variables. Pension funds appear to be substantially less likely to sell than their institutional investor counterparts. In addition, funds are more likely to transact in quarters with a higher TED spread and in quarters with higher total industry assets under management. Among the fund-specific variables, larger and older funds are more likely to transact than smaller and younger funds, consistent with the idea that larger and older funds may be associated with less asymmetric information or lower relative transaction costs. Four to nine-year-old fund transactions are the most common age type in our data in terms of absolute number but the percentage of four-to-nine-year-old funds that transact is smaller than the percentage of older funds that transact. Table 2 also indicates that transacting funds tend to have lower average PMEs at the time of the transaction after controlling for other variates. This finding suggests that sellers tend to bring lower performing funds to market, all else equal.

Columns (3) and (4) of Table 2 report Heckman (1979) estimates of the parameters for the pricing equation given in (27), with the log-book-to-market ratio, $\theta_{i t}$, as the dependent variable. A Campbell-Shiller (1989) decomposition indicates that higher values of $\theta_{i t}$ is associated with either higher market discount rates, lower book discount rates, or higher future book-to-market ratios. We illustrate this decomposition and show empirically that all variation in $\theta_{i t}$ is associated with variation in long run market discount rates in Section 7.1. 
Column (3) of Table 2 indicates that $\theta_{i t}$ tends to be higher when the log-book-to-market ratio for public equities is high, with the coefficient on $\log \left(B M_{t}\right)$ equaling 0.79 (t-statistic $\left.=3.8\right)$. The estimates imply that a one standard deviation shock to $\log \left(B M_{t}\right)$ leads to an expected change in $\theta_{i t}$ of 0.18 , approximately $1 / 3$ of the standard deviation of $\theta_{i t}$. Our index tends to have higher future expected returns when the public book-to-market ratio is high, i.e., when prices for public equities are relatively low. Another important explanatory variable in the pricing equation is the overall industry assets under management $\left(I A U M_{t}\right)$. The coefficient on $I A U M_{t}$ is -0.20 with a $t$ statistic of -2.4. A one standard deviation shock to $I A U M_{t}$ is associated in a change in $\theta_{i t}$ of -0.19 , again, approximately $1 / 3$ of the standard deviation of $\theta_{i t}$. Future expected returns for our index, as indicated by a higher book-to-market ratio, tend to drop with PE assets under management. This finding is similar to that of Pastor, Stambaugh, and Taylor (2015), who find empirical evidence for decreasing returns to scale in active mutual fund management at the industry level.

The coefficient on the inverse Mills ratio in the pricing equation is not significantly different from zero, with a point estimate of 0.06 and a t-statistic of 0.3 . After controlling for our chosen economy-wide and firm-specific characteristics, innovations in price and selection appear to be uncorrelated. In this case, even OLS estimates of the pricing equation are consistent. In fact, the OLS estimates of the pricing equation (columns (5) and (6)), are very close to those of the Heckman estimates of the pricing equation.

\subsection{Private Equity Indices over Time}

We create two equally-weighted market PE indices, one using funds of all ages, and a second using only funds that are 4-9 years old. Figure 2 graphs our private equity indices over the 2006-2018 sample period on a log scale. For comparison we also present the performance of the public equity market (from Ken French's website), two equally-weighted indices based on Preqin reported NAVs, (one using funds of all ages and another using only funds that are four to nine years old), the Burgiss index, and the S\&P Listed Private Equity Index. We create the Preqin indices using the same population of funds that we use to create the secondary market PE indices

and measure the return as the cross-sectional average of $\exp \left(n_{i, t+1}\right)-1$ where $n_{i, t+1}$ is the $\log$ return defined in (19). Our Preqin indices are quite similar to the Burgiss index. The correlation between our Preqin index (all ages) and the Burgiss index is 0.97, while the correlation between our Preqin index (4-9 years) and the Burgiss index is 0.95 . 
Figure 2 illustrates that the two market PE indices are more volatile than the three NAVbased indices (Preqin (all ages), Preqin (4-9 years), and Burgiss). The well-known excessive "smoothness" of NAVs is generally attributed to the use of stale information by general partners. It is also possible that NAVs may not fully reflect variation in market discount rates. We further explore this issue in Section 7.1. The only sharp decline in equity markets during our sample period occurred during the 2008 Financial Crisis. During this period, the NAV indices declined somewhat because assets were written down, but did not decline nearly as much as public equity markets. In contrast, the decline in the market PE indices over 2008 is similar to that in public equity markets. Over 2008 the public equity market index declined 37\%, the S\&P Listed Private Equity Index declined 64\%, while the secondary market PE index (all ages) declined 60\%. Our Preqin NAVbased index (all ages), on the other hand, only fell by 25\%, and the Burgiss NAV-based index dropped by only $27 \%$ during 2008 . Even though private equity NAVs were written down by nearly one quarter of their value during the 2008 Crisis, their actual value most likely declined similar to public equity markets at that time.

\subsection{Risk and Return of Private Equity Indices}

In this section we report estimates of expected returns, beta, alpha, volatility, and Sharpe ratios for the secondary market PE indices of buyout funds. To implement the Dimson (1979) adjustment, we report regressions of index returns on lagged market returns in Table 3 . The first column reports estimates for the secondary market PE indices, while the remaining columns contain estimates for the $S \& P$ Listed Private Equity Index, Preqin, and Burgiss indices. We compute standard errors by GMM using the Newey West (1987) estimate of the spectral density matrix. $^{16}$

Each of the NAV-based indices loads significantly on lagged market returns through three lags. The $S \& P$ Listed Private Equity Index appears to be uncorrelated with lagged market returns. We find that the secondary market PE indices load significantly on lagged market returns through only one lag. The estimates in Table 3 suggest that when applying adjustments based on Dimson (1979), we should account for cross-autocorrelation with market returns at one lag for the

\footnotetext{
${ }^{16}$ The secondary market PE indices contain measurement error that is reasonably independent of the actual index return. Since this measurement is reflected in the dependent variables of our regressions, it is absorbed in the regression residuals.
} 
secondary market PE indices, at three lags for the NAV-based indices, and zero lags for the $S \& P$ Listed Private Equity Index.

Table 4 reports index parameter estimates for the various indices including the secondary market PE indices. For this table we compute GMM standard errors using the Newey West (1987) spectral density matrix along with the delta method, as needed. Consistent with Figure 2, the estimates in Table 4 indicate that buyout funds have performed well over our sample period. The average return for the secondary market PE index using funds of all ages is $14 \%$ and using funds that are $4-9$ years old is $22 \%$. In contrast, NAV-based index returns have averaged from $11-14 \%$, while the $S \& P$ Listed PE Index averaged a return of only $9 \%$ over our sample period.

The betas for our secondary market PE index using funds of all ages ais 1.79, and using 49 year-old funds is 1.76. These estimates are larger than most betas reported in prior literature. As discussed above in previous sections, betas estimated using cash flow data are unlikely to pick up variation in PE discount rates that are manifest in actual market prices for PE. To understand the magnitude of our estimate, recall that private equity funds are portfolios of equity positions in leveraged buyouts. Since buyouts tend to be much more highly levered than public firms, Modigliani-Miller Proposition 2 implies that buyouts should have substantially higher betas than public firms. For example, Axelson, Jenkinson, Strömberg, and Weisbach (2013) report a mean debt-to-total-capital ratio of $70 \%$ in their sample of $1,157 \mathrm{LBOs}$, with mean leverage closer to $50 \%$ during our 2006-2018 sample period. In contrast, typical large publicly traded firms have approximately a $20-25 \%$ debt-to-total-capital ratio. If the firms experiencing buyouts have asset betas equal to 1 , that reflect both discount-rate and cash-flow effects, and debt betas are positive but relatively small, the equity portion of the LBO should nonetheless have a beta close to 1.601.80 , which is consistent with our estimates. ${ }^{17}$

For the secondary market PE index using funds of all ages, we document an alpha of -2\% annually. The vast majority of the literature finds that buyout funds outperform after accounting for risk manifest in PE cash flows. Our alpha accounts for both the covariance of cash flows with the SDF, as well as the covariance of discount rates with the SDF. The alpha of the secondary market PE index using 4-9 year-old funds is estimated to be relatively high at 6\% annualized (though insignificant). It's possible that funds may tend to perform better as they acquire assets, though we cannot reject the null that the alpha for 4-9 year-old funds is zero.

\footnotetext{
${ }^{17}$ See Axelson, Sorensen, and Strömberg (2014) for more discussion.
} 
Using $\log$ returns we find betas of 1.94 using funds of all ages and 1.85 using 4-9 year-old funds. The adjusted alphas under the normal assumption for both indices are both very close to zero. We report these results together with those of other robustness tests in Appendix Table 1.

The S\&P Listed Private Equity Index produces a beta of 1.74, which is similar to that of our secondary market PE indices. Average returns and alphas, however, are quite different. The $S \& P$ Listed $P E$ index earned an average a return of $9 \%$ (t-statistic of 1.0$)$ and an alpha of $-7 \%$ over our sample period (t-statistic of -2.7).

Relative to other indices in Table 4, the estimated volatilities and betas for the NAV indices are quite low. These results suggest that NAV-based indices, even after Dimson adjusting, fail to capture important dynamics in private equity that are related to public equity markets, such as variation in discount rates. We further explore this issue in Section 7.1. Adding more lags to the Dimson adjustment does cause the betas of NAV-based indices to become more similar those of the transaction-based indices or the $S \& P$ Listed Private Equity Index. ${ }^{18}$ In addition, there is a large difference in volatility between the secondary market PE indices (about 34\%) and the NAV-based indices (ranging from $14 \%$ to $20 \%$ ). The volatility of the S\&P Listed Private Equity Index (30\%) is also larger than the NAV-based indices. We provide evidence in Section 7.1 that NAV-based indices do not fully account for variation in market PE discount rates, which represents another cause for NAV smoothness above and beyond stale information.

\section{Discount Rate Risk in Private Equity}

In this section we address two questions. First, how much do private equity discount rates vary over time? Second, to what degree does variation in discount rates create a wedge between standard and cash-flow-based measures of performance? To answer the first question, we run regressions of long-run private equity secondary market returns on log book-to-market ratios motivated by the Campbell-Shiller (1988) present value identity. To answer the second question, we empirically investigate the relative importance of the two components of GPME in the decomposition of equation (11), discounted one-period NPVs and PE discount rate risk.

\footnotetext{
${ }^{18}$ Even if we include seven lags in the Dimson adjustment as suggested by Metrick and Yasuda (2010), we find that NAV-based betas over our sample period are only 0.73 to 0.85 .
} 


\subsection{Variation in Book-to-Market Ratios and Discount Rates}

In this section we explore how much private equity discount rates vary over time. Equation (20) shows that the difference in log market returns and log-book returns can be written as a linear function of book-to-market ratios to a first-order approximation (Vuolanteenaho (2002)). Taking a cross-sectional average of the relation specified in (20) across funds, we obtain

$$
\frac{1}{N} \sum_{i=1}^{N} n_{i, t+1}-r_{i, t+1}=\frac{1}{N} \sum_{i=1}^{N} \rho_{i, t+1} \theta_{i, t+1}-\theta_{t},
$$

which can be written as

$$
\bar{n}_{t+1}-\bar{r}_{t+1}=\bar{\rho}_{t+1} \bar{\theta}_{t+1}-\bar{\theta}_{t}+\bar{c}_{\rho \theta, t+1},
$$

where $\bar{c}_{\rho \theta, t+1}$ denotes the empirical covariance between $\rho_{i, t+1}$ and $\theta_{i, t+1}$ in the cross section across funds, Other parameters are self-explanatory. As explained in Section 4.2 and Appendix A, the approximation parameter, $\rho_{i, t+1}$, can only take on one of three values, all close to 1.0. Not surprisingly, we empirically find time series variation in $\bar{\rho}_{t+1}$ to be trivially small, with a quarterly standard deviation of about 0.01 over our sample. Further, the mean value of $\bar{\rho}_{t+1}$ across time is statistically indistinguishable from 1.0. We therefore motivate the empirical exercise of this section by setting $\bar{\rho}_{t+1}=1$ in each quarter.

Iterating on (30) through time $t+k$ after setting $\bar{\rho}_{t+1}=1$ and taking expectations conditional on information at time $t$ we obtain,

$$
\bar{\theta}_{t}=\sum_{j=1}^{k} E_{t}\left[\bar{r}_{t+j}\right]-\sum_{j=1}^{k} E_{t}\left[\bar{n}_{t+j}\right]+E_{t}\left[\varepsilon_{t+k}\right]
$$

where $\varepsilon_{t+k}$ represents a variable given by

$$
\varepsilon_{t+k}=\sum_{j=1}^{k} \bar{c}_{\rho \theta, t+j}+\theta_{t+k}
$$

Equation (31) says that variation in the average log book-to-market ratio, $\bar{\theta}_{t}$, must be associated with variation in market $\mathrm{PE}$ discount rates, $E_{t}\left[\bar{r}_{t+j}\right]$, variation in book discount rates used to compute NAV, $E_{t}\left[\bar{n}_{t+j}\right]$, or variation in $E_{t}\left[\varepsilon_{t+k}\right]$. We can better understand this variation by regressing long-run market returns, long run book returns, and long run values of $\varepsilon_{t+k}$ on $\bar{\theta}_{t}$ in three separate regressions. 


$$
\begin{gathered}
\sum_{j=1}^{k} \bar{r}_{t+j}=a_{r}+\beta_{r} \bar{\theta}_{t}+w_{r, t+k} \\
-\sum_{j=1}^{k} \bar{n}_{t+j}=a_{n}+\beta_{n} \bar{\theta}_{t}+w_{n, t+k} \\
\varepsilon_{t+k}=a_{\varepsilon}+\beta_{\varepsilon} \bar{\theta}_{t}+w_{\varepsilon, t+k}
\end{gathered}
$$

Given the relation provided in (31) it follows that

$$
1=\beta_{r}+\beta_{n}+\beta_{\varepsilon} .
$$

We can interpret the slope coefficients, $\beta_{r}, \beta_{n}$, and $\beta_{\varepsilon}$ as the fraction of variation in $\bar{\theta}_{t}$ associated with variation in market PE discount rates, book PE discount rates, and $E_{t}\left[\varepsilon_{t+k}\right]$ (Cochrane (2011)).

In Table 5 we report results for the slope coefficient for the three regressions given in (33). Panel A reports results for $k=1$ quarter. These results are for non-overlapping regressions of quarterly realizations of $\bar{r}_{t+j}, \bar{n}_{t+j}$, and $\varepsilon_{t+k}$ on lagged values of $\bar{\theta}_{t}$. Panels B and $\mathrm{C}$ report results for overlapping regressions where $k=4$ ( 1 year) and $k=20$ (5 years). We compute HansenHodrick (1980) standard errors that account for the overlapping returns in our regressions, taking the estimated book-to-market ratios from our index as given.

In Panel A we see that at the quarterly horizon, about $89 \%$ of the variation in book-tomarket ratios is associated with variation in $E\left[\varepsilon_{t+k}\right]$. The value of $\beta_{\varepsilon}$ in Panel $\mathrm{A}$ is estimated to be 0.89 , is highly significant, and the R-squared for this regression is $75 \%$. This result is driven by covariation between current and lagged book-to-market ratios. Regressing $\bar{c}_{\rho \theta, t+1}$ alone on $\bar{\theta}_{t}$ produces an insignificant slope coefficient of 0.0002 .

In Panel B of Table 5 we see that at longer horizons, more variation in book-to-market ratios is explained by variation in market discount rates. In the regression of annual returns on book-to-market ratios one year prior given in Panel $\mathrm{B}$, the estimated value of $\beta_{r}$ is 0.45 , is highly significant, and the R-squared is $7 \%$. Still in Panel B, most of the variation in book to-market ratios is associated with variation in $\varepsilon_{t+k}$. The estimated value of $\beta_{\varepsilon}$ in Panel $\mathrm{B}$ is 0.83 and the Rsquared for this regression is $41 \%$.

In Panel $\mathrm{C}$ of Table 5, the estimated value of $\beta_{r}$ for the regressions of 5-year returns on book-to-market ratios five years prior is 1.65 , is highly significant, and the R-squared is $54 \%$. In contrast, estimates of $\beta_{n}$ and $\beta_{\varepsilon}$ are insignificant in Panel C. In fact, estimates of $\beta_{n}$ are 
insignificant in all panels, and in Panel $\mathrm{C}$, the point estimate of $\beta_{n}$ is negative. The negative coefficient on $\beta_{n}$ is consistent with the hypothesis that book discount rates respond weakly to and are positively correlated with market discount rates. ${ }^{19}$

Expected long-run returns in (31) are given by $\beta_{r} \bar{\theta}_{t}$, and an estimate of the variation in long-run expected PE returns is given by $\beta_{r}^{2} \operatorname{Var}\left(\bar{\theta}_{t}\right)$. We estimate $\operatorname{Var}\left(\bar{\theta}_{t}\right)$ to be 0.048 , implying that the standard deviation of long-run expected returns is 0.36 . Cochrane (2011) estimates the standard deviation of long run expected public equity returns over a five-year horizon to be 0.29 , implying that PE discount rates vary about as much as those for public equity, if not slightly more. In contrast, the standard deviation of book discount rates is only 0.10 . NAVs are too smooth, not only because they reflect stale information, but also because they fail to reflect variation in market discount rates for PE.

The primary implication of Table 5 is that variation in PE book-to-market ratios for private equity is attributable to variation in long run market-discount rates. None of the variation significantly corresponds to variation in long run book-discount rates or variation in expected future book-to-market ratios. This is a pervasive phenomenon that has been documented for other asset classes including public equities, treasuries, credit, foreign exchange, and sovereign debt. ${ }^{20}$ The results of this paper highlight the fact that performance measures based on cash flow data are unlikely to adequately account for variation in prices driven by variation in discount rates.

\subsection{Decomposing GPME}

We estimate the unconditional expected GPME using funds in our market private equity index using funds of all ages,

$$
E\left[G P M E_{i}\right]=E\left[\sum_{j=1}^{T-t} M_{t: t+j} X_{i, t+j}\right],
$$

as a simple average of the "realized" GPME, $\sum_{j=1}^{T-t} M_{t: t+j} X_{i, t+j}$, across funds where $X_{i, t+1}$ and $X_{i, T}$ represent the first capital call and last distribution for fund $i$, and $M_{t: t+j}$ is the realized SDF over

\footnotetext{
${ }^{19}$ Consider a regression of negative book returns on market returns, $-\sum_{j=1}^{k} \bar{n}_{t+j}=\gamma_{0}+\gamma_{1} \sum_{j=1}^{k} \bar{r}_{t+j}+z_{t+k}$. Then $\operatorname{Cov}\left(-\sum_{j=1}^{k} \bar{n}_{t+j}, \bar{\theta}_{t}\right)=\gamma_{1} \operatorname{Cov}\left(\sum_{j=1}^{k} \bar{r}_{t+j}, \bar{\theta}_{t}\right)+\operatorname{Cov}\left(z_{t+k}, \bar{\theta}_{t}\right)$ and $\beta_{n}=\gamma_{1} \beta_{r}+\beta_{z}$ where $\beta_{z}$ is the slope coefficient in a regression of $z_{t+k}$ on $\bar{\theta}_{t}$. In this case, $\beta_{n}$ may be less than zero if $\gamma_{1}$ is sufficiently negative (implying a positive relationship between book and market returns) and $\beta_{z}$ is sufficiently small. For five-year returns we estimate $\gamma_{1}$ to be -0.39 and $\beta_{z}$ to be 0.20 . A similar explanation illustrates why $\beta_{r}$ is above 1.0 . ${ }^{20}$ Cochrane (2011) provides a summary of the literature.
} 
the corresponding time period. We build our market private equity index using funds with recorded cash flows in Preqin from 2006 through 2018. The vintages of these funds span from 1988 through 2018. We scale all cash flows to a $\$ 1$ commitment and use NAV as a terminal value for funds not yet liquidated by the end of our sample.

Our approach to estimate GPME and to conduct inferences is identical to that in Korteweg and Nagel (2016), ${ }^{21}$ and here we highlight only a few details. We define the SDF as,

$$
M_{t: t+j}=\exp \left(a_{0} j+a_{1} r_{m, t: t+j}\right)
$$

where $r_{m, t: t+j}$ is the $\log$ market return from $t$ to $t+j$, and $a_{0}$ and $a_{1}$ are parameters chosen to price two benchmark funds created for each PE fund such that average benchmark GPMEs across funds are both equal to zero. The two benchmark funds for PE fund $i$ invest all capital in either the public market index or short-term t-bills, and the timing of their capital calls and distributions mimic the timing of flows to PE fund $i$ in the sample. To conduct inferences, we compute a GMM $J$-statistic for the test that GPME pricing errors across all funds are zero.

We find the GPME for our funds in our index to be 0.270 with a $J$-statistic p-value of 0.31 . Korteweg and Nagel (2016) report the GPME for venture capital funds of pre-1998 vintage to be 0.423 and of post 1998 vintage to be 0.048 . Our point estimate of the GPME for buyout funds in our index is about two-thirds that of venture funds pre-1998, a period of strong performance for venture funds. Although economically meaningful, the point estimate is not statistically significantly different from zero, highlighting the general difficulty of precisely measuring GPME with short samples and overlapping cash flows. We also find the average annualized IRR for the funds in our index to be $14.42 \%$.

In contrast, the annualized unconditional CAPM alpha for our secondary market PE index is $-2 \%$ (reported in Column 1 of Table (4)), or about -50 basis points per quarter, and is not statistically significantly different from zero. As equation (11) shows, performance measures based on secondary market prices, such as one-period NPV and alpha, depend on variation in market discount rates for PE, while GPME does not, and can justify the disparity we find between the positive GPME using funds in our index and the negative alpha of the index itself.

Other reasons, however, might explain the difference in these results that are specific to PE secondary markets, transaction costs, or the manner in which we construct our PE secondary

\footnotetext{
${ }^{21}$ We thank Arthur Korteweg for supplying us with Matlab code to estimate the GPME and to conduct inferences.
} 
market indices. To rule out such explanations, we evaluate a group of investments in public equities where valuations and portfolio construction are transparent, and where transaction costs are relatively low. We create the cash flows for a series of synthetic PE funds that make capital calls and invest in size decile portfolios from 1980 to 2018. To create these synthetic funds, we adopt the same methodology of Korteweg and Nagel (2016) to create benchmark funds. The timing of cash flows for our synthetic funds mimic those of a "representative fund" created by averaging cash flows across all funds in our index after aligning them in fund-inception time. A new fund begins with a capital call every six months, invests capital in its assigned decile portfolio, makes calls and distributions in subsequent years, and liquidates after 10 years. We relegate further details of creating our synthetic funds to Appendix E. The end result is a series of overlapping cash flows for 590 synthetic funds that each make capital calls and invest all capital in one of the size decile portfolios, 59 funds for each decile. Our results are conservative in that our synthetic funds are unlevered.

Table 6 reports results for our set of synthetic funds. Column (1) reports the decile in which the funds invest called capital. In column (2) we report the average IRR for each set of synthetic funds, which range from $12 \%$ to $25 \%$. In column (3) we report the estimated unconditional expected GPME as in (35) for each of the size decile portfolios, and in column (4) we report the p-value of the $J$-statistic. All synthetic funds we create exhibit significantly positive GPME except funds that invest in the largest decile of stocks, for which the GPME is significantly negative. Our test statistics have greater power than those for the GPME of funds in our index because the cash flows for our synthetic funds span a longer time sample and exhibit less-overlap. The GPME for funds in our index (reported above) is 0.27 and is somewhat comparable to that of our synthetic funds that invest in small cap stocks, even though our synthetic funds lack any leverage. In Table 6 the GPME for the smallest decile is 0.512 with a $J$-statistic p-value near zero, and for the second smallest decile is 0.205 with a p-value of 0.03 .

Similar to equation (11) which provides a decomposition for the conditionally expected GPME, we can decompose the unconditionally expected GPME given above in equation (35) into two components ${ }^{22}$

\footnotetext{
${ }^{22}$ Let $\pi_{i, t+1}^{R}$ denote realized NPV at time $t+1, \pi_{i, t+1}^{R}=M_{t: t+1}\left(X_{i, t+1}+p_{i, t+1}\right)-p_{i, t}$. Starting from the definition of $\pi_{i, T}^{R}$ and iterating backwards, we can write the realized GPME as $\sum_{j=1}^{T-t} M_{t: t+j} X_{i, t+j}=\sum_{t=0}^{T-t-1} M_{t: t+j} \pi_{i, t+j+1}^{R}$. Taking unconditional expectations and rearranging gives (37), noting that by definition, $\pi_{i, t}=E_{t}\left[\pi_{i, t+1}^{R}\right]$.
} 


$$
E\left[G P M E_{i}\right]=\sum_{j=0}^{T-t-1} E\left[M_{t: t+j}\right] E\left[\pi_{i, t+j}\right]+\sum_{t=0}^{T-t-1} \operatorname{Cov}\left(M_{t: t+j}, \pi_{i, t+j}\right) .
$$

For each set of synthetic funds, we estimate the first component on the right side of (37), the sum of discounted one-period NPVs (DNPV). Discount factors to measure DNPV, $E\left[M_{t: t+j}\right]$, are the unconditional expectations of the SDF given in (36), for $j=1, \ldots, T$. We have low degrees of freedom in the time series to estimate these expectations as simple averages at long horizons. Hence, we use a second order Taylor series approximation around $E\left[r_{m, t: t+j}\right]=j E\left[r_{m, t: t+1}\right]$, to estimate the expected discount factor. We have greater degrees of freedom to estimate the expected value of the log quarterly market return, $E\left[r_{m, t: t+1}\right]$, as a simple average. In particular, our estimate of the discount factor $E\left[M_{t: t+j}\right]$, is

$$
\hat{E}\left[M_{t: t+j}\right]=\exp \left[j\left(a_{0}+a_{1} \bar{r}_{m, t}\right)\right]+0.5 a_{1}^{2} \exp \left[j\left(a_{0}+a_{1} \bar{r}_{m, t}\right)\right] j \sigma_{m, t}^{2},
$$

where $\bar{r}_{m, t}$ and $\sigma_{m, t}^{2}$ represent the average and variance of the quarterly market return. For each group of funds that invests in a given decile, we use the same SDF parameters, $a_{0}$ and $a_{1}$ that we use to estimate the GPME for funds in that decile. Over our sample, we estimate $\bar{r}_{m, t}$ to be $2.7 \%$ and $\sigma_{m, t}^{2}$ to be $0.69 \%$.

Let $\pi_{t+j+1}^{R}=\left(X_{i, t+j+1}+p_{i, t+j+1}\right)-p_{i, t+j}$ denote the realized one-period NPV. By definition, $\pi_{t+j}=E_{t+j}\left[\pi_{t+j+1}^{R}\right]$, and it follows by iterated expectations that $E\left[\pi_{t+j+1}^{R}\right]=E\left[\pi_{t+j}\right]$. For each fund we therefore estimate the unconditional expected sum of discounted one-period NPVs, DNPV, as an average of $D N P V_{i}$ across funds,

$$
D N P V_{i}=\sum_{j=0}^{T-t-1} \hat{E}\left[M_{t: t+j}\right] \pi_{t+j+1}^{R}
$$

We estimate the GMM J-statistic recommended by Korteweg and Nagel (2016) to test the null that the average discounted one-period NPVs across all funds ais zero, taking estimated discount factors as given.

As reported in Table 6, DNPVs are insignificant for all deciles except decile 1. The point estimate for DNPV is also largest for funds that invest in decile 1 , at 0.317 with a $J$-statistic pvalue near zero. This result is consistent with a small-cap premium over our sample, which extends from 1980 to the present. Since the GPME for decile 1 is 0.512, the discount-rate risk component of (37) comprises about half of the GPME for funds that invest in this decile. For other small-cap 
deciles DNPVs are relatively close to zero and insignificant. For these deciles, virtually all of the GPME is due to the PE discount rate risk component of (37), not large one-period NPVs. The potential welfare gains of tilting towards PE implied by the GPME measure disappear after accounting for small-cap discount rate risk. For larger deciles, point estimates for DNPV get progressively larger, but are insignificant from zero, and are not as relevant for comparing with our results for buyout funds that, for the most part, invest in small cap firms.

Finally, for each decile portfolio we also estimate the standard one-period alpha as the intercept of the regression

$$
r_{d, t}-r_{f}=\alpha_{d}+\beta_{d}\left(r_{m, t}-r_{f}\right) .
$$

This is the primary parameter of interest for investors holding the market portfolio that seek to maximize the Sharpe ratio. We estimate GMM standard errors using the Newey West (1987) estimator of the covariance matrix and convert t-statistics to $\mathrm{p}$-values for consistency with other results in the table. Standard alphas reported in column (7) for each decile portfolio are all insignificant and very close to zero for all deciles, except decile 1 . The alpha for the decile 1 portfolio is 0.023 with a p-value of 0.01 again, consistent with a small-cap premium over our sample. The alphas for most other deciles are slightly negative.

In summary, our results indicate that GPME can reflect CAPM alpha when it exits, but that GPME can also be rather large and positive even when CAPM alpha is zero or even negative. These findings are based on unlevered synthetic funds. Applying leverage would further amplify our results and widen the gap between GPME and CAPM alpha. These results help bridge the divide between our estimated GPME for funds in our index of 0.27 and an estimated annualized alpha of -0.02 . Comparing these results from those of Table 6 , it appears unlikely that other reasons specific to PE secondary markets, transaction costs, or the manner in which we construct our PE secondary market indices can explain the disparity between the large positive GPME we

find for funds in our index, and the negative alpha we document for the index itself. The low alpha appears to reflect discount rate effects on prices that are not accounted for by GPME which only accounts for the covariation of realized cash flows with the SDF.

\section{Conclusion}

Measuring the performance of private equity investments has historically only been possible using cash-flow data. However, in recent years, a secondary market has developed in 
which investors in private equity funds can trade their stakes. Prices from this market provide a source of data useful for measuring the risk and return of private equity funds in a similar manner to that commonly used to measure returns for other securities.

We construct indices of buyout performance using a proprietary database of secondary market prices of private equity stakes between 2006 and 2018. Analysis of the index indicates that discount rates in private equity vary considerably, an insight that is not readily available from cashflow based measures of private equity performance. This result is confirmed in multiple empirical analyses. First, we decompose the Korteweg and Nagel (2016) GMPE framework into two components. The first reflects the risk-neutral discounted sum of one-period NPVs in each period over a funds life, and the second captures the covariance of the investor's marginal utility with PE discount rates. We find evidence that PE outperformance based on cash-flow based measures such as GPME are driven almost entirely by the covariance of the investor's marginal utility with discount rates, not large one-period NPVs. We also show in simple Campbell-Shiller decomposition regressions that all of the variation in log book-to-market ratios can be explained by variation in market discount rates, as opposed to book discount rates. The implication of these results is that buy-and-hold private equity investors might be exposed to unidentified risk when making capital allocation decisions.

Our estimates indicate that the secondary market PE indices of buyout funds track public equity much more closely than NAV-based indices we consider. The hedonic buyout indices we construct have market betas in the 1.79 range, consistent with the notion that buyouts with increased leverage have higher betas, in marked contrast to the NAV-based indices, whose Dimson-adjusted betas are estimated to be around 0.8. Even after adjusting for known staleness in NAV's, estimated betas from NAV-based indices likely understate the extent to which private equity returns depend on market-wide factors.

The buyout indices we construct have a number of potential uses for investors. Better estimates of private equity risk and return should affect the optimal portfolio decisions of investors when deciding on the allocation to private equity in their portfolios. In addition, the indices can be used to provide more accurate valuations of stakes in private equity funds that investors hold in a manner similar to the "matrix pricing" approach commonly used to price illiquid bonds. Appendix F describes such an approach and provides annual estimates of market values for 2002-2014 vintage funds. Our estimates suggest that the use of NAV for valuation as is done by most LPs can 
be misleading, and that NAVs often substantially misstate the value of an investor's private equity holdings. For example, the market-to-book ratios of funds during the financial crisis reached as low as 0.60 and were as large as 1.4-1.5 in the years coming out of the crisis. Improving these valuations is likely to affect investors' decisions about both the portfolio allocations and the amount they spend from their invested assets.

Undoubtedly, there are uses for the indices we have not discussed in this paper. For example, one could design derivative contracts based on an index of private equity returns. These derivatives could potentially be useful to investors or GPs who wish to hedge risks in their portfolios, or to speculate on the performance of the buyout sector. Better indices of private equity performance such as the ones presented here clearly have much to offer the private equity community. 


\section{References}

Andanov, Aleksandar, Yael V.Hochberg, and Joshua D. Rauh (2017), Political Representation and Governance: Evidence from the Investment Decisions of Public Pension Funds, The Journal of Finance, forthcoming.

Ang, Andrew, Bingxu Chen, William N. Goetzmann, and Ludovic Phalippou (2018), Estimating Private Equity Returns from Limited Partner Cash Flows, The Journal of Finance, 78(4), 1751-1783

Axelson, Ulf, Tim Jenkinson, Per Strömberg, and Michael S. Weisbach (2013) Borrow Cheap, Buy High? The Determinants of Leverage and Pricing in Buyouts. The Journal of Finance, 68 (6), 2223-2267.

Axelson, Ulf, Morten Sorensen, and Per Strömberg (2014), Alpha and Beta of Buyout Deals: A Jump CAPM for Long-term Illiquid Investments, Working paper, London School of Economics.

Blume, Marshall E., and Robert F. Stambaugh (1983), Biases in Computed Returns, Journal of Financial Economics, 12(3), 387-404.

Brunnermaier, Markus K., and Lasse H. Pedersen (2009), Market Liquidity and Funding Liquidity, Review of Financial Studies, 22, 2201-2238.

Buchner, Axel, and Rudiger Stucke, 2014, The systematic risk of private equity, Working paper, University of Passau and University of Oxford.

Campbell, John Y., 1991, A variance decomposition for stock returns, Economic Journal 101, 157-179.

Campbell, John Y., and Robert J. Shiller, 1988, The dividene-price ratio and expectations of future dividends and discount factors, Review of Financial Studies 1, 195-228.

Chen, Zhuo, and Andrea Lu (2018), A Market-Based Funding Liquidity Measure, Working Paper.

Cochrane, John H., 2005, The risk and return of venture capital, Journal of Financial Economics 75, 1, 352.

Cochrane, John H., 2011, Presidential address: discount rates, Journal of Finance 66, 4, 1047-1108.

Dimmock, Stephen G., Neng Wang, and Jinqiang Yang (2019), The Endowment Model and Modern Portfolio Theory, NBER Working Paper Number 25559.

Dimson, Elroy (1979), Risk Measurement When Shares are Subject to Infrequent Trading, Journal of Financial Economics, 7, 197-226.

Driessen, Joost, Tse-Chun Lin, and Ludovic Phalippou (2012), A New Method to Estimate Risk and Return of Nontraded Assets from Cash Flows: The Case of Private Equity Funds, Journal of Financial and Quantitative Analysis, 47(3), 511-535.

Ewens, Michael, Charles M. Jones, and Matthew Rhodes-Kropf (2013), The Price of Diversifiable Risk in Venture Capital and Private Equity, Review of Financial Studies, 26(8), 2013. 
Frazoni, Francesco, Eric Nowak, and Ludovic Phalippou (2012), Private Equity Performance and Liquidity Risk, Journal of Finance, 67(6), 2341-2373.

Gatzlaff, Dean H., and Donald R. Haurin (1998), Sample Selection and Biases in Local House Value Indices, Journal of Urban Economics, 43(2), 199-222.

Gornall, Will, and Ilya A. Strebulaev (2018), Squaring Venture Capital Valuations with Reality, Journal of Financial Economics, forthcoming.

Groh, Alexander P. and Oliver Gottschalg, 2011, The effect of leverage on the cost of capital of US buyouts, Journal of Banking and Finance 35, 2099-2110.

Gupta, Arpit, and Stijn van Nieuwerburgh, 2018, Valuing private equity investments strip by strip, Working paper, New York University.

Hall, Notes on Sample Selection Models (2000), Working Paper, University of Oxford.

Hansen, Lars Peter, and Robert J. Hodrick, 1980, Forward exchange rates as optimal predictors of future spot rates: An econometric analysis, Journal of Political Economy 88, 829-853.

Harris, Robert S., Tim Jenkinson, and Steven N. Kaplan (2014), Private Equity Performance: What do We Know? Journal of Finance, 69(5), 1851-1882.

Heckman, James J. (1974) Shadow Prices, Market Wages, and Labor Supply, Econometrica, 42(4), 679694.

Heckman, James J. (1979), Sample Selection Bias as a Specification Error, Econometrica, 47(1), 153-161.

Higson, Chris and Rudiger Stucke (2012), The Performance of Private Equity, Working Paper.

Hochberg, Yael V. and Joshua D. Rauh (2012), Local Overweighting and Underperformance: Evidence from Limited Partner Private Equity Investments, Review of Financial Studies, 26, 403-451.

Hwang, Min., John M. Quigley, and Susan E. Woodward (2005), An Index for Venture Capital, The B.E. Journal of Economic Analysis and Policy, 4(1), 1-45.

Jegadeesh, Narasimhan, Roman Kraussl, and Joshua M. Pollet (2015), Risk and Expected Returns of Private Equity Investments: Evidence Based on Market Prices, Review of Financial Studies, 28(12), 3269-3302.

Kaplan, Steven N., and Antoinette Schoar (2005), Private Equity Performance: Returns, Persistence, and Capital Flows, Journal of Finance, 60(4), 1791-1823.

Kaplan, Steven N., and Jeremy C. Stein (1990), How Risky is the Debt in Highly Leveraged Transactions? Journal of Financial Economics, 27, 215-245.

Korteweg, Arthur and Stefan Nagel (2016), Risk Adjusting the Returns to Venture Capital, The Journal of Finance, forthcoming.

Lerner, Josh, Antoinette Schoar, and Wan Wongsunwai (2007), Smart Institutions, Foolish Choices: The Limited Partner Performance Puzzle, Journal of Finance, 62, 731-764. 
Ljungqvist, Alexander and Matthew Richardson (2003), The Cash Flow, Return, and Risk Characteristics of Private Equity, NBER Working Paper 9454.

Lo, Andrew and Craig McKinlay (1990) An Econometric Analysis of Nonsynchronous Trading, Journal of Econometrics, 45, 181-211.

McCourt, Maurice, 2018, Estimating skill in private equity performance using market data, Working paper, University of Melbourne.

Metrick, Andrew and Ayako Yasuda, (2010) Venture Capital and the Finance of Innovation, John Wiley and Sons.

Nadauld, Taylor D., Berk A. Sensoy, Keith Vorkink, and Michael S. Weisbach (2019), The Liquidity Cost of Private Equity Investments: Evidence from Secondary Market Transactions, Journal of Financial Economics, 132, 158-181.

Newey, Whitney, and Kenneth D. West, 1987, A simple, positive semi-definite, heteroscedasticity and autocorrelation consistent covariance matrix. Econometrica, Vol 55, 3, 703-708.

Pakes, Ariel (2003), A Reconsideration of Hedonic Price Indexes with an Application to PC's, American Economic Review, 93(5), 1578-1596,

Pastor, Lubos, Robert F. Stambaugh, and Lucian A. Taylor, 2017, Do funds make more when they trade more?, Volume 72, 4, 1483-1528.

Peng, Liang (2001), Building a Venture Capital Index, Yale ICF Working Paper No. 00-51.

Phalippou, L., (2012), Performance of Buyout Funds Revisited? Working Paper.

Philaippou, Ludovic and Oliver Gottschalg (2009), The Performance of Private Equity Funds, Review of Financial Studies, 22(4), 1747-1776.

Politis, Dimitris N., and Joseph P. Romano (1994), Large Sample Confidence Regions Based on Subsamples under Minimal Assumptions, Annals of Statistics, 22 2031-2050.

Politis, Dimitris N., Joseph P. Romano, and Michael Wolf (1999), Subsampling, Springer, New York.

Robinson, David T., and Berk A. Sensoy (2013), Do Private Equity Fund Managers Earn Their Fees? Compensation, Ownership, and Cash Flow Performance, Review of Financial Studies, 11(1), 2760-2797.

Roll, Richard (1984), A Simple Implicit Measure of the Effective Bid-Ask Spread in an Efficient Market, The Journal of Finance, 39(4), 1127-1139.

Scholes, Myron and Joseph Williams (1977), Estimating Betas from Nonsynchronous Data, Journal of Financial Economics, 5(3) 309-327.

Sensoy, Berk A., Yingdi Wang, and Michael S. Weisbach (2014), Limited Partner Performance and the Maturing of the Private Equity Industry, Journal of Financial Economics, 112, 320-343.

Stafford, Erik, 2017, Replicating private equity with value investing, homemade leverage, and hold-tomaturity accounting, Working paper, Harvard Business School. 
Van Binsbergen, Jules, and Michael W Brandt, 2015, Optimal asset allocation in asset liability management, Handbook of Fixed Income, w12970.

Vuolteenaho, Tuomo 2002, What drives firm-level stock returns? Journal of Finance 57, 233-264.

White, Halbert (1982), Maximum Likelihood Estimation of Misspecified Models, Econometrica, 50(1) 125 .

Whyte, Amy (2017), Survey: Endowments and Foundations Unfazed by Private Equity Valuations, Institutional Investor, www.institutionalinvestor.com.

Wooldridge, Jeffrey M. (2010) Econometric Analysis of Cross-Section and Panel Data, MIT Press. 


\section{Appendix}

\section{Appendix A. Returns from Book-to-Market Ratios}

In this appendix we demonstrate the derivation of Equation (20) of the paper. Let the log return on a given $\mathrm{PE}$ fund be defined as

$$
r_{t+1}=\ln \left(\frac{P_{t+1}+X_{t+1}}{P_{t}}\right)
$$

where $P_{t}$ is the market value of the portfolio at time $t$, and $X_{t}$ represents cash flows (total distributions minus capital calls) for the portfolio from $t-1$ to $t$. Equation (A.1) is for a single fund but here we omit fund-level subscripts for notational ease. Note that $X_{t}$ may be positive, negative, or zero. Similarly, define the $\log N A V$-based return as

$$
n_{t+1}=\ln \left(\frac{N A V_{t+1}+X_{t+1}}{N A V_{t}}\right)
$$

If $X_{t+1} \neq 0$ then it follows that the difference in these two return measures can be written as

$$
\begin{aligned}
n_{t+1}-r_{t+1} & =\ln \left(\frac{N A V_{t+1}+X_{t+1}}{\left|X_{t+1}\right|}\right)-\ln \left(\frac{P_{t+1}+X_{t+1}}{\left|X_{t+1}\right|}\right)-\theta_{t} \\
& =\ln \left(\exp \left(\eta_{n, t+1}\right)+\gamma_{t+1}\right)-\ln \left(\exp \left(\eta_{r, t+1}\right)+\gamma_{t+1}\right)-\theta_{t}
\end{aligned}
$$

where

$$
\begin{aligned}
\eta_{n, t+1} & =\ln \left(\frac{N A V_{t+1}}{\left|X_{t+1}\right|}\right), \\
\eta_{r, t+1} & =\ln \left(\frac{P_{t+1}}{\left|X_{t+1}\right|}\right), \\
\theta_{t} & =\ln \left(\frac{N A V_{t}}{P_{t}}\right),
\end{aligned}
$$

and

$$
\gamma_{t+1}= \pm 1
$$

where the sign of $\gamma_{t+1}$ depends on the sign of $X_{t+1}$. Vuolteenaho (2002) derives a similar approximation scaling by dividends. Since cash flows for private equity can be negative, unlike common stock dividends, we scale by the absolute value of net cash flows, otherwise $\eta_{n t}$ and $\eta_{r t}$ are not well defined. A first-order Taylor series approximation of (A.3) centered around $\eta_{0}$ implies

$$
\begin{aligned}
n_{t+1}-r_{t+1} & \approx \rho_{t+1}\left(\eta_{n t+1}-\eta_{r t+1}\right)-\theta_{t} \\
& =\rho_{t+1} \theta_{t+1}-\theta_{t},
\end{aligned}
$$

where the constant of approximation $\rho_{t+1}$ is given by 


$$
\rho_{t+1}=\frac{\exp \left(\eta_{0}\right)}{\exp \left(\eta_{0}\right)+\gamma_{t+1}} .
$$

Alternatively, if $X_{t+1}=0$ then the second row of (A.5) holds exactly at $\rho_{t+1}=1$. Hence, we allow the constant of approximation to change depending on whether cash flows are positive, negative, or zero. Equation (A.5) implies

$$
r_{t+1} \approx n_{t+1}-\rho_{t+1}\left(\eta_{n t+1}-\eta_{r t+1}\right)+\theta_{t}
$$

which is equation (20) of the paper.

The median value of $\eta_{n t}$ across all funds/quarters in our sample is about 2.68, corresponding with

$$
\rho_{t+1}=\left\{\begin{array}{l}
0.94 \text { for } \gamma_{t+1}=1 \\
1.07 \text { for } \gamma_{t+1}=-1
\end{array}\right.
$$

Our results are quite robust to this specification and are markedly similar if we specify $\rho_{t+1}$ to be any value in the range from 0.90 to 0.99 for observations with $\gamma_{t+1}=1$, and in the range from 1.01 to 1.10 for observations with $\gamma_{t+1}=-1$. For our main results we specify $\rho_{t+1}$ as in (A.8).

\section{Appendix B. Log Returns}

In this appendix we demonstrate that the realized log return on an equally-weighted portfolio is the average log return across assets in the portfolio to a first-order approximation. Let $R_{1}, \ldots, R_{N}$ denote the gross returns on $N$ assets over a given period. The realized log equallyweighted portfolio return is

$$
r_{p}=\ln \left[\frac{1}{N} \sum_{i=1}^{N} R_{i}\right]=\ln \left[\sum_{i=1}^{N} e^{r_{i}}\right]-\ln (N)
$$

where $r_{i}=\ln \left(R_{i}\right)$. Given that $r_{1}=\cdots=r_{n}=0$, then $r_{p}=0$ and

$$
\left.\frac{\partial r_{p}}{\partial r_{i}}\right|_{r_{i}=0}=\frac{1}{N} .
$$

Hence, to a first-order approximation around the point $r_{1}=r_{2}=\cdots=r_{N}=0$,

$$
r_{p} \approx \frac{1}{N} \sum_{i=1}^{N} r_{i}
$$




\section{Appendix C. Dimson Adjusted Volatility}

In this Appendix we present a method to bias-adjust volatility when observed returns can be characterized by the model of Dimson (1979), who presumes that securities trade intermittently at the ends of specified periods. Similar to Dimson (1979), assume that observed index returns, $\hat{r}_{t}$, may be written as

$$
\hat{r}_{t}=\sum_{j=0}^{l} \lambda_{j} r_{t-j}+u_{t}
$$

where $r_{t}$ represents the i.i.d. "true" portfolio return based on end of quarter values and $u_{t}$ is a mean zero i.i.d. error term. From (D.1) it follows that

$$
\operatorname{Cov}\left(\hat{r}_{t}, \hat{r}_{t-1}\right)=\sum_{j=1}^{l} \lambda_{j} \lambda_{j-1} \operatorname{Var}\left(r_{t}\right)
$$

or rather,

$$
\operatorname{Var}\left(r_{t}\right)=\frac{\operatorname{Cov}\left(\hat{r}_{t}, \hat{r}_{t-1}\right)}{\sum_{j=1}^{l} \lambda_{j} \lambda_{j-1}}
$$

Let $a$ and $\beta$ denote the parameters of a linear projection of $r_{t}$ on the contemporaneous market return, $r_{m, t}$. We can then write

$$
\hat{r}_{t}=c+\sum_{j=0}^{l} \psi_{j} r_{m, t-j}+\varepsilon_{t}
$$

where $c$ is a constant, $\psi_{j}=\lambda_{j} \beta$ and $\varepsilon_{t}=\sum_{j=0}^{l} \epsilon_{t-j}+u_{t}$ is i.i.d. and mean zero. Dimson (1979) assumes $\sum_{j=1}^{l} \lambda_{j}=1$, which implies $\sum_{j=1}^{l} \psi_{j}=\beta$. To estimate the variance us in (D.3) we jointly estimate $\operatorname{Cov}\left(r_{t}, r_{t-1}\right)$ and $\psi_{0}, \ldots, \psi_{m}$ by GMM. We then estimate $\lambda_{j}$ as $\lambda_{j}=\psi_{j} / \sum_{j=0}^{l} \psi_{j}$ and compute the variance by scaling the auto-covariance as in (D.3). We use this volatility adjustment when computing Sharpe raios and correlation as well. We compute standard errors for $\operatorname{Var}\left(r_{t}\right)$ from the GMM covariance matrix of estimated parameters via the delta method. 


\section{Appendix D. Data Details}

In this appendix we describe how we clean our data. From the transactions data we first pull all records for which their "detailed strategy" is classified as "Buyout". We then identify unique funds by their fund names, hand checking fund names that appear similar. We omit funds labeled as parallel funds, feeder funds, annex funds, sub funds, top-up funds, duplicate funds, coinvestment funds, supplemental funds, and side-cars. We then clean the transactions data as follows:

1) Eliminate all funds with a total commitment less than $\$ 500 \mathrm{M}$.

2) Eliminate transactions with a price less than zero.

3) Eliminate transactions with a NAV less than zero.

4) Eliminate transactions that have the same price for every fund in the portfolio transaction.

6) Eliminate transactions for which the total amount committed by the seller minus the unfunded commitment is less than zero.

7) Eliminate transactions for which the total capital committed is less than or equal to zero.

8) Eliminate transactions for which the fund name is missing.

9) If multiple transactions occur on the most recent transaction date for a given fund/quarter, use only the transaction based on the highest total commitment.

10) If multiple transaction records exist with the same fund name and commitment on the most recent transaction date for a given fund/quarter, choose one of these transactions at random as the transaction that represents the end-of-quarter transaction price.

12) Eliminate all remaining transactions for which the price, as a percent of NAV, is greater than 3 standard deviations away from the mean price across funds for a given quarter.

After pulling data from Preqin for funds with a "category_type" equal to "Buyout", we clean the data as follows:

1) Eliminate any fund-quarters for which $N A V_{i, t-1}=0$, or the NAV-based return is otherwise missing. Note that we retain records for which $N A V_{i, t}=0$. Once NAV hits zero, however, we no longer include the fund in the sample.

2) Eliminate stale NAVs, those with a report date prior to 30 days before the end of each quarter. 
3) Identify fund-quarters for which the NAV-based return is greater than 3 standard deviations from the mean across all funds for a given quarter. These returns appear to be inconsistent with reported IRRs from Preqin.

We then merge our Preqin data with the explanatory variables described in Table 2, and then merge these data with the cleaned transactions dataset. To merge the transaction and cashflow data, we first identify funds with identical fund names in the two databases and designate these as a match. We then identify fund names in the transaction and Preqin data that are "similar" and that also have the same vintage. Fund names A and B are considered similar if fund name A contains the first 5 characters of fund name $B$ anywhere in the fund name string or vice-versa. We then hand check this list to determine which funds match. After merging we have data on 703 unique funds, 355 of which account for 955 transactions during our sample period from March of 2006 through June of 2018.

\section{Appendix E. Synthetic Funds that Invest in Public Equities}

To create synthetic PE funds that invest in public equities, we first identify the timing of flows for a "representative fund" that includes all funds in our secondary market-based PE index. The index includes funds with recorded cash flows in Preqin from 2006 through 2018 with vintages spanning from 1988 through 2018. Using this population of funds, we scale all fund flows to a $\$ 1$ commitment, align flows in fund-inception-time (as if they all made their initial capital call at the same moment) and calculate the average net flows across funds each quarter from fund inception to liquidation. We use NAV as a terminal value for funds not-yet liquidated by the end of the sample, and eliminate funds with an initial capital call after December 312016. These average flows represent the flows of our representative fund and are illustrated in Appendix Figure E1. The initial capital call in our sample averages about 9 cents and average drawdowns in subsequent quarters fall in the range of 3 to 5 cents. Average net flows first turn positive in quarter 14 when funds are almost 4 years old, and climb to a peak of 5.02 cents at quarter 28 when funds are almost 7 years old. Net flows then slowly decline to zero. The longest lasting fund in

our sample paid out its last distribution in the $87^{\text {th }}$ quarter following its initial capital call. The average fund in our sample lasts between 9 and 10 years. 
Using the flows of the representative fund, we then use the approach of Korteweg and Nagel (2016) to create the cash flows for a series of replicating funds that invest in public equities. These authors develop this methodology to create benchmark funds to use in estimating SDF parameters when calculating GPME. We initially use the same methodology for a different purpose, to create the cash flows of synthetic funds that we wish to evaluate and price.

We first sort stocks into size deciles each month, and for each decile, create the cash flows for 59 artificial funds that make capital calls and invest the acquired capital into the assigned size decile portfolio. Funds start with a cash flow of zero at the end of June or December of their given initial year, year ${ }_{i}$, and respectively make their first capital call at the end of September of year $r_{i}$ or March of year +1 . For example, fund 1 makes its first capital call at the end of March, 1980, fund 2 makes its first capital call at the end of September, 1980, and so forth, with the last fund, fund 59, making its first capital call March of 2009. Following the algorithm, capital calls each quarter are identical to those of the representative fund in fund-inception time. If the representative fund makes a payout at the end of quarter $q$ in fund-inception time, the artificial funds also make payouts at the end of quarter $q$ equal to the sum of two components. The first component is equal to the return accumulated since the last quarter in which a call or distribution was made. The second component is equal to a fraction, $f_{q}$, of the remaining capital under management with

$$
f_{q}=\min \left(\frac{q-p}{40-p}, 1\right)
$$

where $p$ is the time of the most recent payout prior to quarter $q$, measured in fund-inception time quarters. If the payout at quarter $q$ is the fund's first payout, then $p=0$. This assumption sets the life of each artificial fund to 10 years, and for our setup implies that the 59th fund pays its final distribution December of 2018. We proceed in this manner to create the overlapping cash flows for 59 artificial funds that invest capital in their assigned size-decile portfolio, and then repeat this exercise for all 10 deciles.

\section{Appendix F. An Application: "Matrix Pricing" of Private Equity Funds}

Most funds are valued by limited partners at the NAV, which can deviate substantially from the best available estimate of the fund's underlying value. These valuations are used for a number of purposes by investors in funds, including portfolio allocation decisions across asset 
classes, and spending decisions, which are usually set by investors as a fixed percentage of a portfolio's assessed value. Examples of this policy approach include universities and foundations. More accurate pricing of limited partner stakes in private equity funds may improve the ability of investors to make investment decisions since it may lead to portfolio allocations and spending rules corresponding to better estimates of the underlying values of an institution's private equity investments.

One possible approach to value stakes in private equity funds more accurately is to follow a procedure similar to "Matrix Pricing," commonly used to price bonds, by which the prices of bonds that do not trade are determined based on the prices of bonds that do. The idea is that the same fundamentals affect similar bonds in the same manner, so prices of bonds that do not trade likely move approximately the same amount as prices of similar bonds that do trade. Since private equity funds that invest in one type of asset are likely affected by a number of the same shocks to their fundamentals, they can be priced using comparable methods with transactions-based indices.

For any fund, the fund's history of quarterly cash inflows and outflows can be combined with the quarterly returns of the hedonic indices to calculate market values. Beginning at the end of some chosen quarter $t$ we set fund value for fund $i, V_{i, t}$, equal to $N A V$. Then for all subsequent quarters we estimate fund value as

$$
V_{i, t}=V_{i, t-1}\left(1+r_{t}\right)+C_{i, t}-D_{i, t},
$$

where $C_{t}$ and $D_{t}$ denote capital calls and distributions between times $t$ and $t+1$, and $r_{t}$ represents the simple return on our market-based index.

We perform this calculation for each fund in our sample for every quarter in our sample period (2006 to 2018). One version of our market-based index is formed using transactions from funds that are between four and nine years old and we use this version of the index to calculate market values for four-to-nine-year-old funds. Following the procedure described above, we set market value equal to NAV at the end of the fourth year following each fund's vintage year and iterate forward to identify market values at the end of subsequent quarters. ${ }^{23} \mathrm{We}$ report year-end aggregate market-to-book ratios by vintage in Appendix Table F1 by summing year-end market

\footnotetext{
${ }^{23}$ For the 2005 vintage, we set NAV equal to market value at the end of year three due to irregularities in reported NAVs associated with the financial crisis.
} 
values for each fund for a given vintage and dividing by the sum of year-end NAVs for the same set of funds. ${ }^{24}$

Aggregate market-to-book ratios for each vintage across time are reported in the bottom of Appendix Table F1. The average ranges from a low of 0.90 for the 2002 vintage of funds to high of 1.16 for 2004 vintage. Market-to-book ratios are considerably lower during the Financial Crisis, ranging between 0.67 and 0.79 in 2008 for the 3 vintages that were old enough for our hedonic estimation. Funds that invested out of 2007 and 2008 vintage funds did so at lower valuations, and therefore have high average market-to-book ratios in subsequent years when markets recovered. For example, these estimates indicate that by the end of 2015, a 2007 buyout fund has a NAV that is understated by $14 \%$ relative to its market value.

Individual funds could mark their values to market using the approach in one of two ways. The most accurate approach would be to generate fund-specific market values using the estimated coefficients from the pricing models applied to the fund's attributes. A simpler approach, but one that nonetheless represents a substantial improvement over using NAVs, is to multiply the NAV of each of LP's investments by the average market-to-book ratio of the industry. For example, an LP would multiply the NAV of each four-to-nine-year-old fund in his or her portfolio by the appropriate ratio from Appendix Table F1. For younger funds, the deviation between NAVs and market value is likely to be smaller but could be estimated using the coefficients from the pricing model. Tail-end funds will have only a few portfolio companies left and their values will vary depending on the fortunes of these particular investments. As such, this approach is likely to be less useful for valuing these funds.

\footnotetext{
${ }^{24}$ The 2018 market-to-book ratio is reported as of Q2 because of data availability.
} 
Figure 1.

Number of Transactions per Quarter

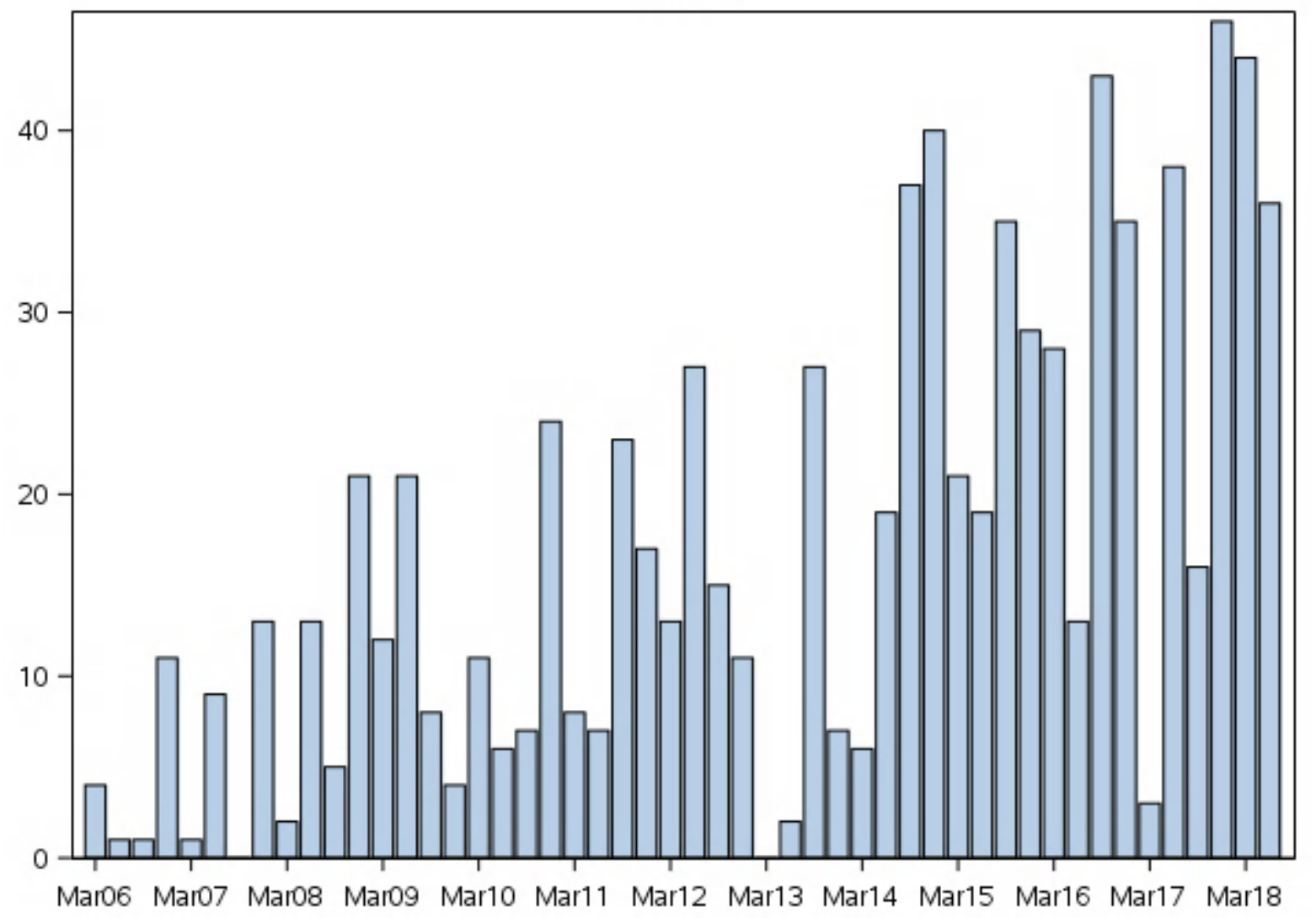


Figure 2. Transactions-Based Buyout Index Over Time

This figure illustrates the value of investing \$1 in an index at the beginning of 2006 in each buyout index as labeled. "Market PE Index All Ages" and "Market PE index 4-9 Yrs" represent the indices we build based on PE secondary market transactions. The "Public Market" index represents the public market return as posted on Ken French's website. "Preqin All Ages" and "Preqin 4-9 Yrs" represent the indices we build using NAVs as reported in Preqin for the exact same funds that are in our PE market-based indices. The Burgiss index is a NAV-based buyout index. The $S \& P$ Listed Private Equity Index is an index comprised of publicly traded private equity funds. The chart uses a log scale for the vertical axis.

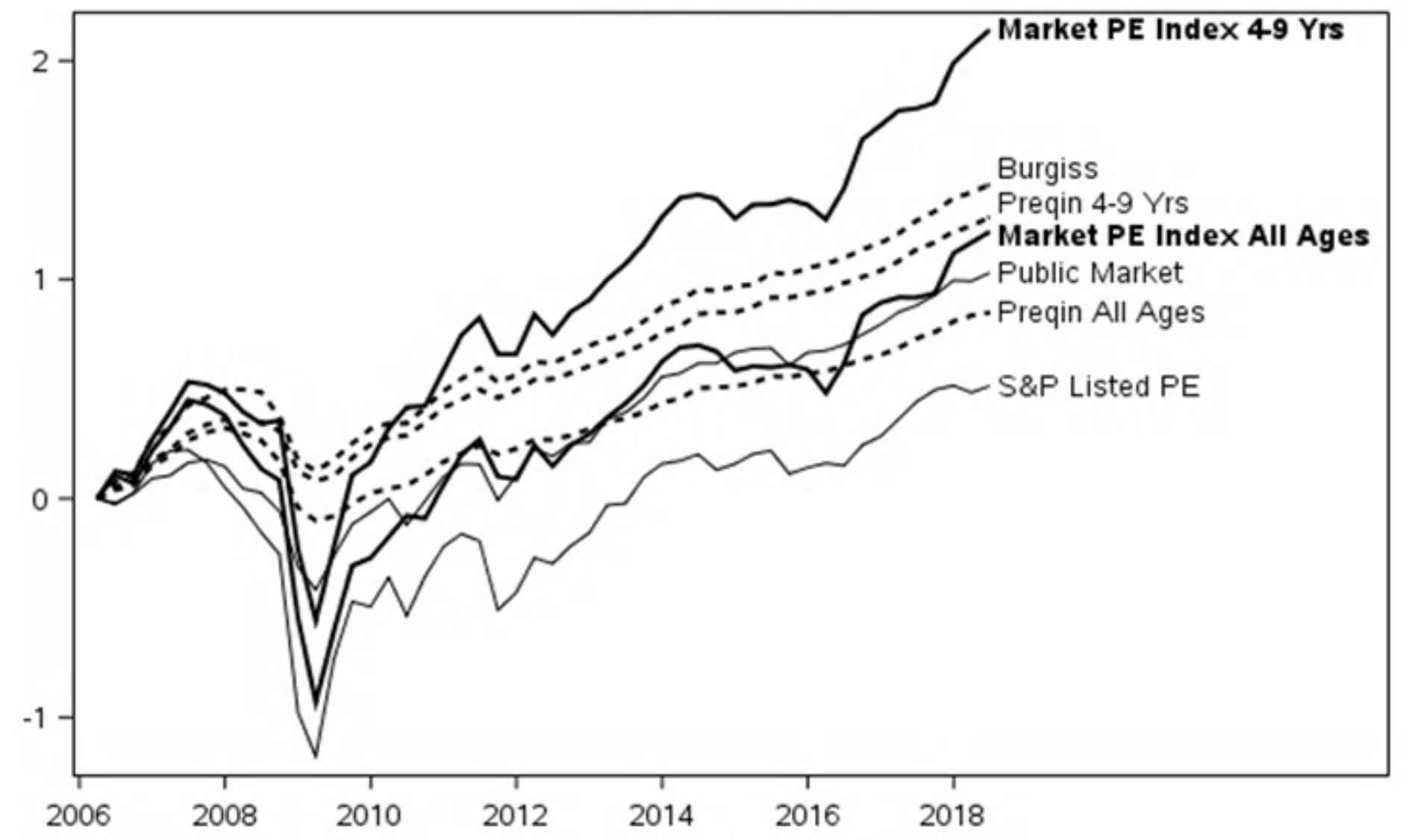


This table reports summary statistics for the variables used in our Heckman regression. The first column reports statistics for the sample of funds that transact. The second column reports statistics for the sample of funds that do not transact. $\theta_{i t}$ is the $\log$ book-to-market ratio of fund $i$ at time $t, A g e_{i t}$ is the age of fund $i$ at time $t, \log \left(\operatorname{siz} e_{i t}\right)$ is the $\log$ of total capital committed for fund $i$ at time $t, P M E_{i, t}$ is the public market equivalent of Kaplan and Schoar (2006) for fund $i$ at time $t$, $P F_{i, t}$ is the fraction of LPs that are pension funds for fund $i$ at time $t, \log \left(B M_{t}\right)$ is the log value-weighted average book-tomarket ratio measured at the end of the month prior to the transaction calculated using stocks with a market cap less than $\$ 500$ million and share code 10 or 11 in CRSP at time $t, I A U M_{t}$ is total assets under management in by the PE industry at time $t$ scaled by the total number of firms that have between 20 and 500 employees as of the end of the prior year as reported by the US Census, TED $D_{t}$ is the TED-spread at time $t$ measured as the spread between 3-month LIBOR based on US dollars and 3-month treasury yields. $N$ per Quarter is the number of observations each quarter in the sample. "Mean" "Median" and "Stdev" represent the average, median and standard deviation across time and across all funds (if applicable), "Q1" is the $25^{\text {th }}$ percentile, and "Q3" is the $75^{\text {th }}$ percentile.

\begin{tabular}{|c|c|c|c|}
\hline \multicolumn{2}{|l|}{ Column } & \multirow{2}{*}{$\begin{array}{c}\text { (1) } \\
\text { Transactions }\end{array}$} & \multirow{2}{*}{$\begin{array}{c}\text { (2) } \\
\text { No Transaction }\end{array}$} \\
\hline & & & \\
\hline \multirow{3}{*}{$\theta_{i, t}$ (dep variable) } & Mean & 0.19 & \\
\hline & Median & 0.10 & \\
\hline & Stdev & 0.42 & \\
\hline \multirow[t]{3}{*}{$\log \left(\operatorname{size}_{i, t}\right)$} & Mean & 21.95 & 21.28 \\
\hline & Median & 21.99 & 21.13 \\
\hline & Stdev & 0.96 & 0.87 \\
\hline \multirow[t]{3}{*}{$\mathrm{Age}_{i, t}$} & Mean & 8.61 & 6.39 \\
\hline & Median & 9.00 & 6.00 \\
\hline & Stdev & 4.05 & 4.15 \\
\hline \multirow[t]{3}{*}{$P M E_{i, t}$} & Mean & 1.15 & 1.13 \\
\hline & Median & 1.10 & 1.06 \\
\hline & Stdev & 0.36 & 0.37 \\
\hline \multirow[t]{3}{*}{$P F_{i t}$} & Mean & 0.53 & 0.56 \\
\hline & Median & 0.55 & 0.57 \\
\hline & Stdev & 0.17 & 0.20 \\
\hline \multirow[t]{3}{*}{$\log \left(B M_{t}\right)$} & Mean & -0.22 & -0.25 \\
\hline & Median & -0.22 & -0.23 \\
\hline & Stdev & 0.24 & 0.26 \\
\hline \multirow[t]{3}{*}{$\operatorname{LAUM}_{t}$} & Mean & 3.29 & 3.28 \\
\hline & Median & 3.53 & 3.53 \\
\hline & Stdev & 0.75 & 0.75 \\
\hline \multirow[t]{3}{*}{$T E D_{t}$} & Mean & 0.48 & 0.47 \\
\hline & Median & 0.33 & 0.32 \\
\hline & Stdev & 0.49 & 0.46 \\
\hline \multirow[t]{3}{*}{ N per Quarter } & Mean & 17.48 & 290.56 \\
\hline & Q1 & 7 & 237 \\
\hline & Q3 & 27 & 353 \\
\hline Quarters & & 48 & 50 \\
\hline$N$ & & 839 & 14,528 \\
\hline
\end{tabular}




\section{Table 2. Heckman Model Estimates}

This table reports the estimates of the Heckman (1979) sample selection model. Columns (1) and (2) reports estimates of parameters for the selection equation while columns (3) and (4) reports estimates for the pricing equation. "Heckman" refers to the sample selection model, while "OLS" indicates the pricing model is estimated by simple OLS with no selection equation or inverse Mills ratio. Variables are described in the heading for Table 1. We estimate the standard errors of model parameters using a panel bootstrap clustering by time. Significance at the $1 \%, 5 \%$, and $10 \%$ levels is indicated, respectively, by “***”, “**”, and “*”.

\begin{tabular}{|c|c|c|c|c|c|c|}
\hline \multirow[t]{4}{*}{ Column } & (1) & (2) & (3) & (4) & (5) & (6) \\
\hline & \multicolumn{4}{|c|}{ Heckman } & \multirow{2}{*}{\multicolumn{2}{|c|}{$\begin{array}{c}\text { OLS } \\
\text { Pricing }\end{array}$}} \\
\hline & \multicolumn{2}{|c|}{ Selection } & \multicolumn{2}{|c|}{ Pricing } & & \\
\hline & estimate & (t-stat) & estimate & (t-stat) & estimate & (t-stat) \\
\hline $\log \left(B M_{t}\right)$ & -0.03 & $-(0.1)$ & 0.79 & $(3.8) * * *$ & 0.79 & $(5.1)^{* * *}$ \\
\hline$T E D_{t}$ & 0.31 & $(2.0)^{* *}$ & -0.05 & $-(0.4)$ & -0.06 & $-(0.9)$ \\
\hline $\operatorname{LAUM}_{t}$ & 0.20 & $(2.2)^{* *}$ & -0.20 & $-(2.4) * *$ & -0.21 & $-(3.3)^{* * *}$ \\
\hline $\log \left(\right.$ size $\left._{i, t}\right)$ & 0.40 & $(13.4)^{* * *}$ & 0.00 & $(0.0)$ & -0.02 & $-(1.9)^{*}$ \\
\hline$I(A g e<4)$ & -0.50 & $-(4.1)^{* * *}$ & 0.15 & $(0.8)$ & 0.18 & $(2.6)^{* * *}$ \\
\hline$I($ Age>9) & 0.33 & $(4.6) * * *$ & 0.20 & $(1.7)^{*}$ & 0.18 & $(4.0)^{* * *}$ \\
\hline$P M E_{i, t}$ & -0.13 & $-(2.0)^{* *}$ & -0.08 & $-(1.5)$ & -0.07 & $-(2.2)^{* *}$ \\
\hline$P F_{i, t}$ & -0.32 & $-(2.8)^{* * *}$ & & & & \\
\hline Inv Mills Ratio & & & 0.06 & $(0.3)$ & & \\
\hline Intercept & -10.66 & $-(14.7)^{* * *}$ & 1.05 & $(0.3)$ & 1.65 & $(5.6)^{* * *}$ \\
\hline $\mathrm{N}$ (selected) & 839 & & 839 & & 839 & \\
\hline $\mathrm{N}$ (not selected) & 14,528 & & & & & \\
\hline
\end{tabular}


Table 3. Predicting Index Returns Using Lagged Market Returns

This table reports estimates from regressions of index returns on contemporaneous and lagged market returns. The transaction index returns are generated using the Heckman model to control for sample selection and are equal-weighted. We build the Preqin indices based on NAVs reported in Preqin using funds in the market-based PE indices. The Burgiss index is a NAV-based buyout index. The S\&P Listed Private Equity Index is an index comprised of publicly traded private equity funds.

\begin{tabular}{|c|c|c|c|c|c|c|c|c|c|c|}
\hline \multirow[t]{3}{*}{ Column } & (1) & (2) & (3) & (4) & (5) & (6) & (7) & $(8)$ & (9) (10) & \multirow{2}{*}{$\frac{(11) \quad(12)}{\text { Burgiss }}$} \\
\hline & \multicolumn{4}{|c|}{ Transactions } & \multirow{2}{*}{\multicolumn{2}{|c|}{ S\&P Listed }} & \multicolumn{3}{|c|}{ Preqin NAV } & \\
\hline & \multicolumn{2}{|c|}{ All Ages } & \multicolumn{2}{|c|}{ 4-9 Yrs Old } & & & \multicolumn{2}{|c|}{ All Ages } & 4-9 Yrs Old & \\
\hline a & -0.01 & $-(0.79)$ & 0.01 & $(1.35)$ & -0.01 & $-(1.36)$ & 0.00 & $-(0.88)$ & $0.01(2.11) * *$ & $0.01(1.25)$ \\
\hline $\mathrm{b}_{0}$ & 1.24 & $(4.78) * * *$ & 1.22 & $(5.01) * * *$ & 1.71 & $(7.54) * * *$ & 0.42 & $(5.95) * * *$ & $0.40(7.30) * * *$ & $0.50(7.70) * * *$ \\
\hline$b_{1}$ & 0.60 & $(4.33) * * *$ & 0.59 & $(4.53) * * *$ & 0.01 & $(0.07)$ & 0.15 & $(5.48) * * *$ & $0.14(6.12) * * *$ & $0.12(3.62) * * *$ \\
\hline$b_{2}$ & -0.27 & $-(1.20)$ & -0.32 & $-(1.46)$ & -0.32 & $-(1.56)$ & 0.10 & $(3.31) * * *$ & $0.07(3.26) * * *$ & $0.11(2.74) * * *$ \\
\hline$b_{3}$ & 0.24 & $(1.93)^{*}$ & 0.22 & $(1.55)$ & 0.03 & $(0.23)$ & 0.12 & $(2.68) * * *$ & $0.09(2.13) * *$ & $0.10(2.17) * *$ \\
\hline$b_{4}$ & -0.13 & $-(0.86)$ & -0.19 & $-(1.39)$ & -0.06 & $-(0.75)$ & 0.04 & $(1.03)$ & $0.01(0.19)$ & $0.01(0.19)$ \\
\hline $\mathrm{N}$ & 45 & & 45 & & 45 & & 45 & & 45 & 45 \\
\hline
\end{tabular}


This table reports index parameters for buyout indices using data from 2006-2018. Column (1) reports results for our transactions-based indices using funds of all ages, column (2) reports results for our transactions-based indices using funds that are 4-9 years old, column (3) reports results for the S\&P listed index, columns (4) and (5) report results for our Preqin NAV-based indices using funds that are in the transaction-based indices. Moments of indices are Dimson adjusted using $x$ lags based on results from Table 3. We estimate standard errors for index parameters by GMM using the approach of Newey and West (1987) to estimate the spectral density matrix and the delta method. Significance at the $1 \%$, $5 \%$, and $10 \%$ levels is indicated, respectively, by “***”, “**”, and “*”.

\begin{tabular}{|c|c|c|c|c|c|c|c|c|c|c|}
\hline \multirow[t]{3}{*}{ Column } & (1) & (2) & (3) (4) & (5) & (6) & (7) & (8) & (9) & (10) & \multirow{3}{*}{$\begin{array}{c}\text { (11) (12) } \\
\text { Burgiss }\end{array}$} \\
\hline & \multicolumn{3}{|c|}{ Transactions } & \multirow{2}{*}{\multicolumn{2}{|c|}{ S\&P Listed }} & \multicolumn{4}{|c|}{ Preqin NAV } & \\
\hline & \multicolumn{2}{|c|}{ All Ages } & 4-9 Yrs Old & & & \multicolumn{2}{|c|}{ All Ages } & \multicolumn{2}{|c|}{ 4-9 Yrs Old } & \\
\hline $\mathrm{E}[\mathrm{r}]$ & 0.14 & $(1.6)$ & $0.22(2.5)^{* *}$ & 0.09 & $(1.0)$ & 0.11 & $(3.4) * * *$ & 0.14 & $(4.6) * * *$ & $0.12(3.2) * * *$ \\
\hline$\beta$ & 1.79 & $(8.0)^{* * *}$ & $1.76(8.7)^{* * *}$ & 1.74 & $(8.1)^{* * *}$ & 0.72 & $(5.7)^{* * *}$ & 0.64 & $(5.9) * * *$ & $0.81(5.7)^{* * *}$ \\
\hline$\alpha$ & -0.02 & $-(0.4)$ & $0.06(1.1)$ & -0.07 & $-(2.7)^{* * *}$ & 0.04 & $(1.6)$ & 0.07 & $(3.3)^{* * *}$ & $0.04(1.6)$ \\
\hline$\sigma$ & 0.34 & $(4.3) * * *$ & $0.31(4.0) * * *$ & 0.30 & $(4.2) * * *$ & 0.17 & $(2.5)^{* *}$ & 0.14 & $(2.8) * * *$ & $0.20(2.1)^{* *}$ \\
\hline Sharpe & 0.41 & (1.3) & $0.68(1.9) *$ & 0.27 & $(1.3)$ & 0.67 & $(2.3) * *$ & 0.99 & $(2.7)^{* * *}$ & $0.60(1.9)^{*}$ \\
\hline Corr w/ Mkt & 0.83 & $(4.0) * * *$ & $0.88(3.7)^{* * *}$ & 0.90 & $(2.0)^{* *}$ & 0.70 & $(1.7)^{*}$ & 0.76 & $(1.8)^{*}$ & $0.65(1.6)$ \\
\hline $\mathrm{AC}$ (unadjusted) & 0.30 & $(0.8)$ & $0.26(0.7)$ & 0.22 & $(0.5)$ & 0.54 & (1.4) & 0.41 & $(0.8)$ & $0.46(1.3)$ \\
\hline $\mathrm{N}$ (Pricing) & 839 & & 839 & & & & & & & \\
\hline $\mathrm{N}$ (Selection) & 15,367 & & 15,367 & & & & & & & \\
\hline $\mathrm{N}$ (Index) & 49 & & 49 & 49 & & 49 & & 49 & & 49 \\
\hline
\end{tabular}


Table 5. Campbell-Shiller Regressions

This table reports the slope coefficient in Campbell-Shiller regressions as described in the paper. In Panel A the dependent variables are measured at a quarterly (non-overlapping) horizon. In Panel B, dependent variables are measured at an annual horizon, and in Panel C, dependent variables are measured at a five-year horizon. We compute Hanson-Hodrick (1983) standard errors to account for overlapping data. Significance at the 1\%, $5 \%$, and $10 \%$ levels is indicated, respectively, by “***”, “**”, and “*”.

\begin{tabular}{|c|c|c|c|}
\hline Column & (1) & (2) & (3) \\
\hline & paramete & st. err & R-sq \\
\hline & \multicolumn{3}{|c|}{ Panel A. $k=1$ quarter } \\
\hline$\beta_{r}$ & 0.06 & $(0.12)$ & 0.01 \\
\hline$\beta_{n}$ & 0.03 & $(0.04)$ & 0.03 \\
\hline$\beta_{\varepsilon}$ & 0.89 & $(0.08)^{* * *}$ & 0.75 \\
\hline \multirow[t]{2}{*}{$\mathrm{N}$} & 49 & & \\
\hline & \multicolumn{3}{|c|}{ Panel B. $k=4$ quarters } \\
\hline$\beta_{r}$ & 0.45 & $(0.43)$ & 0.07 \\
\hline$\beta_{n}$ & 0.01 & $(0.17)$ & 0.00 \\
\hline$\beta_{s}$ & 0.83 & $(0.26)^{* * *}$ & 0.41 \\
\hline \multirow[t]{2}{*}{$\mathrm{N}$} & 46 & & \\
\hline & \multicolumn{3}{|c|}{ Panel C. $k=20$ quarters } \\
\hline$\beta_{r}$ & 1.65 & $(0.50)^{* * *}$ & 0.54 \\
\hline$\beta_{n}$ & -0.44 & $(0.29)$ & 0.22 \\
\hline$\beta_{\varepsilon}$ & 0.05 & $(0.60)$ & 0.00 \\
\hline $\mathrm{N}$ & 30 & & \\
\hline
\end{tabular}


Table 6. Performance Metrics for Unlevered Synthetic Funds that Invest in Small-Cap Stocks

This table reports performance metrics for the set of synthetic funds we create. We sort stocks into size deciles each month and create the flows for a set of synthetic funds using the algorithm of Korteweg and Nagel (2016) that separately invest capital in one of the size decile value-weighted portfolios. For each decile, we create a set of funds that make initial capital calls at the end of June and December of each year from December 1979 through December 1984. Each fund invests the acquired capital into their assigned size decile portfolio. For each set of funds, column (2) reports the average IRR, and column (3) reports the GPME of Korteweg and Nagel (2016). Column (5) reports the average risk-neutral discounted abnormal profits across funds in each set. Column (7) reports the standard CAPM alpha for each decile portfolio. Significance at the 1\%, 5\%, and $10 \%$ levels is indicated, respectively, by “***”, “**”, and “*”.

\begin{tabular}{|c|c|c|c|c|c|c|c|c|}
\hline Column & Decile & IRR & GPME & p-value & DNPV & p-value & $\begin{array}{c}\text { CAPM } \\
\text { alpha }\end{array}$ & p-value \\
\hline & 1 & 0.25 & 0.512 & $(0.00)^{* * *}$ & 0.317 & $(0.00)^{* * *}$ & 0.023 & $(0.01)^{* *}$ \\
\hline & 2 & 0.10 & 0.205 & $(0.03) * *$ & 0.014 & $(0.15)$ & -0.006 & $(0.37)$ \\
\hline & 3 & 0.09 & 0.168 & $(0.04) * *$ & 0.010 & $(0.25)$ & -0.009 & $(0.14)$ \\
\hline & 4 & 0.09 & 0.193 & $(0.03) * *$ & 0.035 & $(0.20)$ & -0.007 & $(0.24)$ \\
\hline Public Equities & 5 & 0.10 & 0.183 & $(0.01)^{* *}$ & 0.098 & $(0.25)$ & -0.006 & $(0.18)$ \\
\hline \multirow[t]{5}{*}{$1980-2018$} & 6 & 0.11 & 0.164 & $(0.01)^{* * *}$ & 0.134 & $(0.31)$ & -0.005 & $(0.26)$ \\
\hline & 7 & 0.11 & 0.131 & $(0.01)^{* * *}$ & 0.164 & $(0.41)$ & -0.004 & $(0.26)$ \\
\hline & 8 & 0.12 & 0.113 & $(0.00)^{* * *}$ & 0.182 & $(0.44)$ & -0.002 & $(0.55)$ \\
\hline & 9 & 0.13 & 0.088 & $(0.00)^{* * *}$ & 0.159 & $(0.51)$ & -0.001 & $(0.81)$ \\
\hline & 10 & 0.12 & -0.034 & $(0.04)^{* *}$ & 0.171 & $(0.74)$ & 0.000 & $(0.69)$ \\
\hline & $\mathrm{N}$ & & 59 Funds & /Decile & 59 Fund & s/Decile & $157 \mathrm{Obs}$ & Decile \\
\hline
\end{tabular}




\section{Appendix Figure 1. Cash Flows for the Representative Fund}

This figure illustrates the cash flows of the representative fund we use to create synthetic funds that invest in stock deciles. These cash flows are the average cash flows of all funds in our index based on fund-inception time. We build our index using funds with recorded cash flows in Preqin from 2006 through 2018 with vintages spanning from 1988 through 2016. We scale all fund flows to a \$1 commitment, align flows in fund-inceptiontime (as if they all made their initial capital call at the same moment) and calculate the average net flows across funds each quarter from fund inception to liquidation. We use NAV as a terminal value for funds not-yet liquidated by the end of the sample.

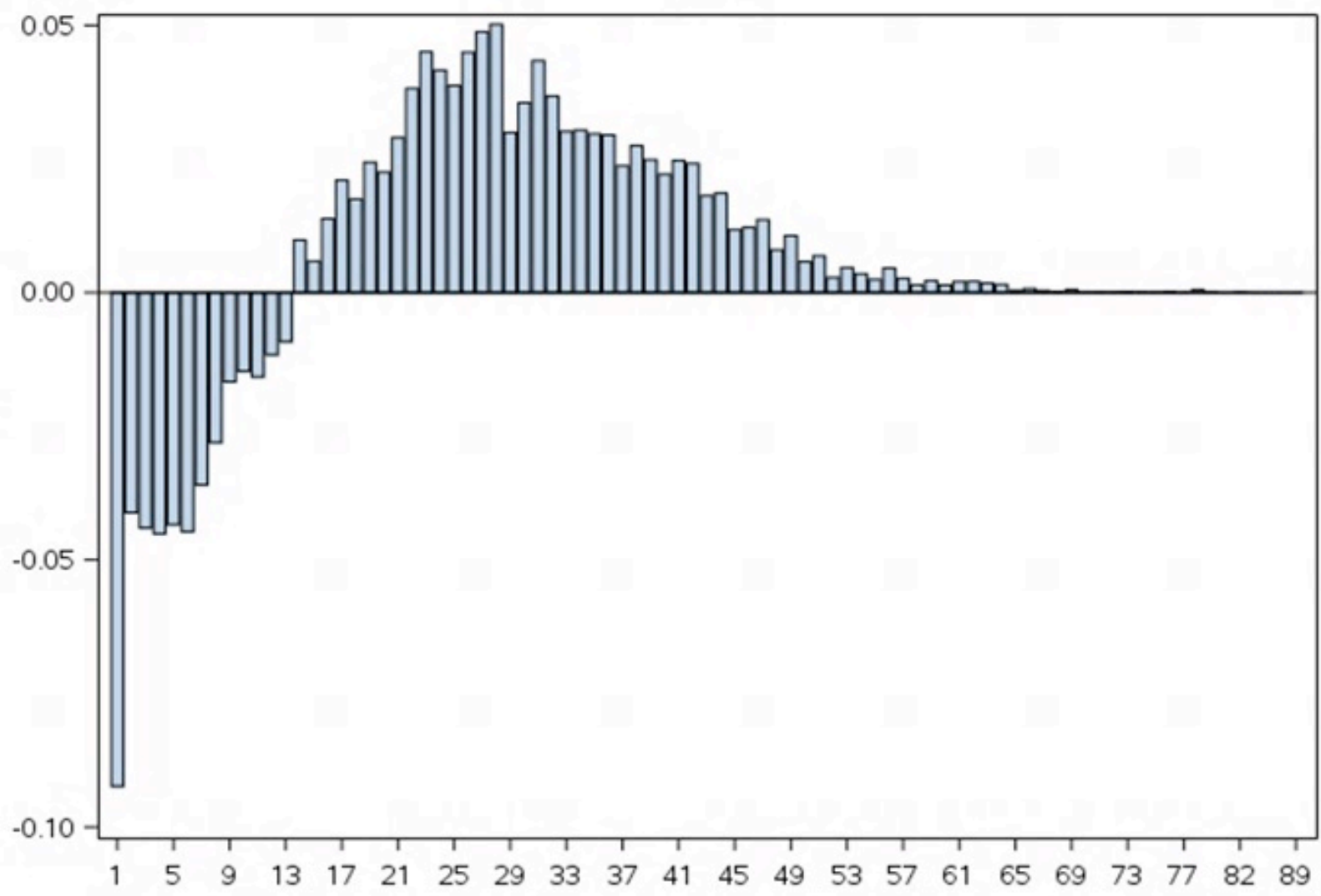




\section{Appendix Table 1. Robustness Checks}

In this table we report main index parameters of interest for different versions of the model and for different methods of estimating index parameters. All expected returns and alphas are annualized. In Panel A we report index parameters for log returns after adjusting alpha as in Cochrane (2005) and Axelson, Sorensen, and Stromberg (2014), $\alpha=\delta+$ $\left[(1 / 2) \sigma_{I}^{2}-(1 / 2) \sigma_{M}^{2}+\beta(1-\beta)\right]$ where $\delta$ denotes the intercept in a regression of log excess index returns on $\log$ excess market returns, $\sigma_{I}^{2}$ denotes the Dimson-adjusted index variance (see Appendix C), $\sigma_{M}^{2}$ denotes the market variance, and $\beta$ denotes the Dimson-adjusted index beta using one lag. All other panels report results using simple (exponentiated) returns after Dimson adjusting as discussed in the text and Appendix C. In Panel B we eliminate insignificant variables from the pricing equation as reported in Columns (3) and (4) of Table 2 before constructing the index and estimating index parameters. In Panels $\mathrm{C}$ and $\mathrm{D}$ we replace state variables in both the pricing and selection equation with quarterly fixed effects. In Panel $\mathrm{C}$ we use the estimated FE from the prior quarter for the two quarters with no transactions (Q3/2007 and Q1/2013). In Panel D we delete the two quarters with missing transactions. This causes use to lose four index return observations. In Panels $\mathrm{E}$ and $\mathrm{F}$ we replace state variables in both the pricing and selection equation with quarterly fixed effects and eliminate all other variables from the pricing equation. In Panel $\mathrm{E}$ we use the estimated FE from the prior quarter for the two quarters with no transactions. In Panel F we delete the two quarters with missing transactions. Standard errors are estimated by GMM using the Newey West (1987) estimate of the spectral density matrix, along with the delta method. Significance at the $1 \%, 5 \%$ and $10 \%$ level of significance is indicated by “***”, “**”, and “*” respectively.

\begin{tabular}{|c|c|c|c|c|c|c|c|}
\hline & \multicolumn{4}{|c|}{ Panel A. Log Returns (Adjusted Alpha) } & \multicolumn{3}{|c|}{ Panel B. Narrow Pricing Eq I } \\
\hline & \multicolumn{2}{|c|}{ All Ages } & \multicolumn{2}{|c|}{ 4-9 Yrs Old } & \multicolumn{2}{|c|}{ All Ages } & 4-9 Yrs Old \\
\hline & (1) & (2) & (3) & (4) & (1) & (2) & (3) (4) \\
\hline $\mathrm{E}[\mathrm{r}]$ & 0.10 & $(1.0)$ & 0.17 & $(1.9) *$ & 0.12 & (1.4) & $0.18(2.1)$ \\
\hline$\beta$ & 1.94 & $(6.1)^{* * *}$ & 1.85 & $(6.6)^{* * *}$ & 1.76 & $(8.0) * * *$ & $1.73(7.8)$ \\
\hline$\alpha$ & -0.02 & $(0.0)$ & 0.00 & $(0.0)$ & -0.04 & $-(0.8)$ & $0.02(0.4)$ \\
\hline $\mathrm{N}$ (Pricing) & 839 & & 839 & & 839 & & 839 \\
\hline $\mathrm{N}$ (Selection) & 15,367 & & 15,367 & & 15,367 & & 15,367 \\
\hline \multirow[t]{4}{*}{$\mathrm{N}$ (Index) } & 49 & & 49 & & 49 & & 49 \\
\hline & \multicolumn{4}{|c|}{ Panel C. Quarter Fixed Effects I } & \multicolumn{3}{|c|}{ Panel D. Quarter Fixed Effects II } \\
\hline & \multicolumn{2}{|c|}{ All Ages } & \multicolumn{2}{|c|}{ 4-9 Yrs Old } & \multicolumn{2}{|c|}{ All Ages } & 4-9 Yrs Old \\
\hline & (1) & $(2)$ & (3) & (4) & & (2) & (3) (4) \\
\hline $\mathrm{E}[\mathrm{r}]$ & 0.16 & $(1.0)$ & 0.23 & $(1.4)$ & 0.16 & $(0.9)$ & $0.22(1.2)$ \\
\hline$\beta$ & 1.64 & $(3.0) * * *$ & 1.63 & $(3.0) * * *$ & 1.77 & $(3.4)$ & $1.77(3.4) * * *$ \\
\hline$\alpha$ & 0.01 & $(0.1)$ & 0.08 & $(0.5)$ & 0.00 & $(0.0)$ & $0.06(0.4)$ \\
\hline N (Pricing) & 839 & & 839 & & 839 & & 839 \\
\hline N (Selection) & 15,367 & & 15,367 & & 14,835 & & 14,835 \\
\hline \multirow[t]{4}{*}{$\mathrm{N}$ (Index) } & 49 & & 49 & & 45 & & 45 \\
\hline & \multicolumn{4}{|c|}{ Panel E. Quarter Fixed Effects III } & \multicolumn{3}{|c|}{ Panel F. Quarter Fixed Effects IV } \\
\hline & \multicolumn{2}{|c|}{ All Ages } & \multicolumn{2}{|c|}{ 4-9 Yrs Old } & \multicolumn{2}{|c|}{ All Ages } & 4-9 Yrs Old \\
\hline & (1) & (2) & (3) & (4) & (1) & (2) & (3) (4) \\
\hline $\mathrm{E}[\mathrm{r}]$ & 0.17 & $(1.0)$ & 0.22 & (1.3) & 0.18 & $(1.0)$ & $0.23(1.2)$ \\
\hline$\beta$ & 1.98 & $(3.8)^{* * *}$ & 1.96 & $(3.7)^{* * *}$ & 2.05 & $(3.9)^{* * *}$ & $2.04(3.8)^{* * *}$ \\
\hline$\alpha$ & -0.01 & $-(0.1)$ & 0.04 & $(0.3)$ & 0.00 & $(0.0)$ & $0.05(0.3)$ \\
\hline$N$ (Pricing) & 839 & & 839 & & 839 & & 839 \\
\hline $\mathrm{N}$ (Selection) & 15,367 & & 15,367 & & 14,835 & & 14,835 \\
\hline $\mathrm{N}$ (Index) & 49 & & 49 & & 45 & & 45 \\
\hline
\end{tabular}




\section{Appendix Table 2. Aggregate Market-to-Book Ratios of Private Equity Investments}

This table reports year-end average market-to-book ratios. Market values for each fund are calculated using the following procedure. We begin by assuming that the market value of the fund is equal to NAV in years one through four of the fund's life. We then calculate the market value each quarter from years 5-9 for fund $i$ using the following formula:

$$
V_{i, t}=V_{i, t-1}\left(1+r_{H, t}\right)+C_{i, t}-D_{i, t}
$$

where $V_{i, t}$ is equal to the $N A V$ of fund $i$ at time $t$. $C_{t}$ and $D_{t}$ denote capital calls and distributions between times $t$ and $t+1$, and $r_{H, t}$ represents the return on our hedonic transaction-based index. For the first quarter in year five, we use NAV as the preceding quarter's market value. The aggregate market-to-book ratio reported in this table is calculated as the sum of the individual fund's market value within each quarter divided by the sum of the individual fund's NAV in each quarter. We report the resultant market-to-book ratio for Q4 of each year, with the exception of 2018, where we report values as of Q2 due to data limitations.

\begin{tabular}{|c|c|c|c|c|c|c|c|c|c|c|c|c|c|}
\hline \multicolumn{14}{|c|}{ Vintage Year } \\
\hline & 2002 & 2003 & 2004 & 2005 & 2006 & 2007 & 2008 & 2009 & 2010 & 2011 & 2012 & 2013 & 2014 \\
\hline 2006 & 1.07 & -- & -- & -- & -- & -- & -- & -- & -- & -- & -- & -- & -- \\
\hline 2007 & 0.83 & 0.93 & -- & -- & -- & -- & -- & -- & -- & -- & -- & -- & -- \\
\hline 2008 & 0.59 & 0.60 & 0.76 & -- & -- & -- & -- & -- & -- & -- & -- & -- & -- \\
\hline 2009 & 0.98 & 0.82 & 1.02 & 0.78 & -- & -- & -- & -- & -- & -- & -- & -- & -- \\
\hline 2010 & 1.16 & 0.95 & 1.28 & 1.11 & 1.10 & -- & -- & -- & -- & -- & -- & -- & -- \\
\hline 2011 & 1.35 & 0.95 & 1.32 & 1.31 & 1.06 & 0.98 & -- & -- & -- & -- & -- & -- & -- \\
\hline 2012 & -- & 1.11 & 1.73 & 1.34 & 1.19 & 1.13 & 1.01 & -- & -- & -- & -- & -- & -- \\
\hline 2013 & -- & -- & 2.59 & 1.71 & 1.49 & 1.39 & 1.22 & 1.04 & -- & -- & -- & -- & -- \\
\hline 2014 & -- & -- & -- & 2.58 & 1.51 & 1.28 & 1.07 & 0.86 & 0.88 & -- & -- & -- & -- \\
\hline 2015 & -- & -- & -- & -- & 1.44 & 1.30 & 1.02 & 0.70 & 0.79 & 0.95 & -- & -- & -- \\
\hline 2016 & -- & -- & -- & -- & -- & 1.81 & 1.28 & 0.77 & 1.05 & 1.20 & 0.97 & -- & -- \\
\hline 2017 & -- & -- & -- & -- & -- & -- & 1.60 & 0.70 & 1.14 & 1.30 & 0.96 & 1.14 & -- \\
\hline 2018 & -- & -- & -- & -- & -- & -- & -- & 0.67 & 1.40 & 1.42 & 0.95 & 1.16 & 0.99 \\
\hline Average & 1.00 & 0.89 & 1.45 & 1.47 & 1.30 & 1.31 & 1.20 & 0.79 & 1.05 & 1.22 & 0.96 & 1.15 & 0.99 \\
\hline
\end{tabular}

